\title{
RAE-ELETRÔNICA: EXPLORAÇÃO DO ACERVO À LUZ DA BIBLIOMETRIA, GEOANÁLISE E REDES SOCIAIS
}

\section{RAE-ELETRÔNICA: EXPLORATION OF ARCHIVE IN THE LIGHT OF BIBLIOMETRICS, GEOANALYSIS AND SOCIAL NETWORK}

RAE-ELETRÔNICA: EXPLORACIÓN DEL ACERVO A LA LUZ DE LA BIBLIOMETRÍA, GEOANÁLISIS Y REDES SOCIALES

\section{RESUMO}

Este estudo explora o acervo completo da RAE-eletrônica, composto de 240 artigos em 18 edições, de 2002 a 2010, por meio do uso de técnicas de bibliometria, análise de redes sociais e análise geográfica. Analisa-se o conteúdo, envolvendo títulos, palavras-chave, resumos e o corpo dos textos; colaboração, entre autores e instituições; periódicos e congressos mais influentes; e citações e autocitações, envolvendo autoria e referências bibliográficas. Conclui-se que o acervo da RAE-eletrônica reflete, em grande parte, as características do universo da produção acadêmica recente em Administração no Brasil, devido à maior influência da $R A E$ e de periódicos internacionais, e dos congressos da Anpad. Destacam-se a FGV-EAESP, a USP e a UFRGS como as instituições mais influentes do acervo. Termos como "empresa", "organização" e "trabalho" estão entre os mais mencionados nos textos, enquanto "gestão" é a palavra-chave mais frequente. O uso combinado das técnicas exploradas neste artigo potencializa sua apropriação a outros conjuntos de artigos e campos da produção científica.

PALAVRAS-CHAVE Análise de redes sociais, análise geográfica, bibliometria, coautorias, RAE-eletrônica.

Eduardo de Rezende Francisco eduardo.francisco@aes.com

Doutor em Administração de Empresas pela Escola de Administração de Empresas de São Paulo, Fundação Getulio Vargas São Paulo - SP, e Especialista em Estratégias de Marketing da AES Eletropaulo - São Paulo - SP, Brasil

\begin{abstract}
This study explores the entire archive of RAE-eletrônica, consisting of 240 articles in 18 editions, from 2002 to 2010, using techniques of bibliometrics, social network analysis and geographic analysis. It analyzes the content, involving titles, keywords, summary and body of texts; collaboration between authors and institutions; most influential journals and conferences, and citations and self-citations involving authorship and references. It concludes that the RAE-eletrônica collection largely reflects the characteristics of the universe of recent academic administration production in Brazil, due to the greater influence of RAE and international journals, and Anpad conferences. Highlights are FGV-EAESP, USP and UFRGS as the most influential institutions of the collection. Terms like "company", "organization" and "work" are among the most mentioned in the texts, while "management" is the most frequent keyword. The combined use of the techniques explored in this article leverages its appropriation to other sets of articles and scientific fields.

keywords Social network analysis, geographic analysis, bibliometrics, co-authorships, RAE-eletrônica.

Resumen Este estudio explora el acervo completo de la RAE-eletrônica, compuesto de 240 artículos en 18 ediciones, de 2002 a 2010, por medio del uso de las técnicas de bibliometría, análisis de redes sociales y análisis geográfico. Se analiza el contenido, envolviendo títulos, palabras clave, resúmenes y el cuerpo de los textos; colaboración, entre autores e instituciones; periódicos y congresos más influyentes; y citaciones y autocitaciones, envolviendo autoría y referencias bibliográficas. Se concluye que el acervo de la RAE-eletrônica refleja, en gran parte, las características del universo de la producción académica reciente en Administración en Brasil, debido a la mayor influencia de la RAE y de periódicos internacionales, y de los congresos de la Anpad. Se destacan la FGV-EAESP, Ia USP y la UFRGS como las instituciones más influyentes del acervo. Términos como "empresa", "organización" y "trabajo" están entre los más nombrados en los textos, mientras que "gestión" es la palabra clave más frecuente. El uso combinado de las técnicas exploradas en este artículo potencialaza su apropiación a otros conjuntos de artículos y campos de la producción científica.
\end{abstract}

Palabras clave Análisis de las redes sociales, análisis geográfico, bibliometría, coautorías, RAE-eletrônica. 


\section{INTRODUÇÃ̃o}

Escrever sobre o acervo da RAE-eletrônica no momento em que a $R A E$ completa seu quinquagésimo aniversário é a missão deste artigo. Uma missão honrosa, mas, ao mesmo tempo, despretensiosa. Afinal, uma revista jovem como a RAE-eletrônica, com vida independente de apenas nove anos, torna qualquer conclusão apenas inspiração para um aprofundamento nos 50 anos de história dentro do contexto de uma revista sempre renovada como a $R A E$.

Desde seu lançamento, em maio de 1961, a $R A E$ destaca-se pela relevância, importância, posicionamento científico, contundência e antecipação de tendências no mundo científico, em diversos contextos políticos e econômicos fundamentais. A revista foi a primeira publicação científica na área de Administração de Empresas e mantém-se em publicação ininterrupta, sempre buscando fomentar a produção e disseminação de conhecimento em sua área de atuação, por meio de uma linha editorial generalista, cobrindo um espectro amplo de subdomínios do conhecimento, perspectivas e questões relevantes. Em 2011, a $R A E$ completa 50 anos, sob a égide de liderança no impacto científico de suas publicações.

Por sua vez, a RAE-eletrônica, que surgiu em 2002, com suas 18 edições até 2010, apresenta-se relevante dentro desse contexto (MACHADO-DA-SILVA e outros, 2008). Sua vida independente foi curta, mas intensa, com mais de 200 trabalhos publicados, entre artigos, pensatas e resenhas. Nesse período, cinco editoreschefes imprimiram seus estilos, garantindo a preservação da marca de pioneirismo que caracterizou seu lançamento e a qualidade e rigor com que sempre foi reconhecida. Sua continuidade, a partir de 2011, de maneira integrada à $R A E$ certamente preservará essas características.

Este artigo propõe-se a fazer uma análise exploratória inicial de diversos aspectos do acervo da RAE-eletrônica: (i) conteúdo, envolvendo títulos, palavras-chave, resumos; (ii) colaboração, entre autores, afiliações, periódicos e congressos mais influentes; e (iii) citações e autocitações, envolvendo autoria e referências. Técnicas de mineração de texto (text mining), análise de redes e análises geográficas foram utilizadas. Quando relevante, alguma análise histórica dentro do período é destacada. Algumas conclusões fortalecem estudos mais profundos de colaboração e influência para subcampos específicos da Adminis- tração. Certamente, muitas análises mais detalhadas e desdobramentos advirão das perspectivas aqui abordadas - e esse é um dos objetivos deste trabalho. O emprego desse ferramental para o acervo completo da $R A E$, com seus mais de 2.000 artigos nas 213 edições (até abril/2011), é uma possibilidade vislumbrada que se fortalece.

O tema em si insere-se em um contexto de análise bibliométrica, uma das diversas formas de avaliação do conhecimento científico, de medição de fluxos de informação (VANTI, 2002), da influência de autores, artigos e periódicos em um determinado período ou tema abordado (ARANHA e outros, 2004; FRANCISCO e outros, 2005; MACHADO-DA-SILVA e outros, 2008, por exemplo).

Este artigo está dividido em seis seções, contando com esta introdução. A segunda seção descreve brevemente o ferramental metodológico de análise de redes sociais, bibliometria e análise geográfica utilizadas. As seções terceira a quinta descrevem o acervo da RAE-eletrônica, à medida que discorrem os principais resultados, respectivos à rede de colaboração entre autores e entre afiliações, à rede de autores e citações, e à análise de conteúdo dos artigos. Na sexta e última seção, encontram-se as considerações finais da pesquisa, bem como sugestões para futuros trabalhos.

\section{ANÁLISE BIBLIOMÉTRICA E TÉCNICAS CORRELATAS}

Existem diversas formas de avaliação do conhecimento científico e de medição de fluxos de informação. Entre estas, destacam-se a bibliometria, a cienciometria, a informetria e a webometria (VANTI, 2002). O presente trabalho enfoca e utiliza conceitos das três primeiras dessas metodologias.

A bibliometria é o estudo dos aspectos quantitativos da produção, disseminação e uso da informação registrada com emprego de métodos matemáticos e estatísticos (SPINAK, 1996; TAGUE-SUTCKIFFE, 1992). São quatro os principais tipos de metodologia utilizados pela bibliometria: análise de citações, análise de cocitações, agrupamentos bibliográficos e co-word analysis (CALDAS, TINOCO, CHU, 2003).

A cienciometria, por sua vez, é definida como "a medição do processo informático”, em que o termo 
"informático" significa "a disciplina do conhecimento que estuda a estrutura e as propriedades da informação científica e as leis do processo de comunicação" (SPINAK, 1996, p. 142). O termo cienciometria alcançou notoriedade com o início da publicação, em 1977, da revista Scientometrics, editada originalmente na Hungria e atualmente na Holanda (TAGUESUTCKIFFE, 1992; DOBROV e KARENNOI, 1969). A cienciometria difundiu-se principalmente a partir da década de 1980, alavancada pelo trabalho do Institute for Scientific Information (ISI), orientado para pesquisas na área de ciência da informação e venda de bases de dados para instituições do mundo todo (VANTI, 2002). De acordo com seu fundador, Garfield $(1979,1956)$, a ideia de indexar citações data do final do século XIX, mas apenas na década de 1950 é que métodos computacionais para automatizar essa rotina começaram a ser desenvolvidos; no início da década de 1960, dois projetos pilotos foram desenvolvidos por Garfield e associados, com o apoio de empresas privadas do setor farmacêutico norte-americano e do United States National Institute of Health.

Por fim, a informetria é o estudo dos aspectos quantitativos da informação em qualquer formato, e não apenas registros catalográficos ou bibliográficos; seu alcance está além das publicações científicas. De certa maneira, engloba a bibliometria e a cienciometria, e pode ser utilizada para a análise de difusão de assuntos abordados em comunidades acadêmicas e não acadêmicas (WORMELL, 1998; HJOREGAARD e INGWERSEN, 1997).

Algumas possibilidades de aplicação das técnicas bibliométricas, cienciométricas e informétricas (VANTI, 2002; KOSTOFF, 1998, 1994) são: (i) identificar as tendências e o crescimento do conhecimento em uma área; (ii) identificar as revistas e periódicos do núcleo de uma disciplina; (iii) identificar os principais usuários, pesquisadores, grupos e instituições de uma disciplina; (iv) estudar a dispersão e a obsolescência da literatura científica; (v) prever a produtividade de autores individuais, organizações e países; (vi) medir o grau e padrões de colaboração entre autores; (vii) analisar os processos de citação e cocitação; (viii) avaliar os aspectos estatísticos da linguagem, das palavras e das frases; e (ix) medir o crescimento de determinadas áreas e o surgimento de novos temas.

Tradicionalmente, em estudos dessa natureza, a unidade de análise investigada são os artigos publicados (MARTINS e outros, 2010). Porém, uma avaliação da cooperação entre os autores dos artigos estende os estudos para as manifestações de cola- boração intelectual na pesquisa científica. Por isso, o uso de técnicas de análise de redes vem sendo explorado por diversos estudos recentes (MELLO, CRUBELLATE e ROSSONI, 2009 e 2010; ROSSONI e GUARIDO FILHO, 2009; ROSSONI E MACHADO-DASILVA, 2008; MOODY, 2004; NEWMAN, 2001). Essas técnicas permitem que analisemos as configurações estruturais das redes de autores, de afiliações e de palavras-chave: componentes, densidade, agrupamentos, centralidades, subgrupos (HANNEMAN e RIDDLE, 2005).

Já o emprego de técnicas de análise geográfica no estudo bibliométrico é ainda bastante incipiente. Comumente, o processo de análise de dados espaciais inclui métodos de visualização, métodos exploratórios para investigar algum padrão nos dados (p.e., segmentação) e métodos que auxiliem a escolha de um modelo estatístico e a estimação dos parâmetros desse modelo (CARVALHO, 1997). Podemos dividir as ferramentas da análise espacial em: seleção, manipulação, análise exploratória e confirmação (modelagem), segundo Anselin (1988). Além da percepção visual da distribuição espacial do problema, é muito útil traduzir os padrões existentes em considerações objetivas e mensuráveis, que são endereçadas pela análise espacial de dados geográficos e pela estatística espacial. A ênfase da análise espacial é mensurar propriedades e relacionamentos, levando-se em conta a localização espacial do fenômeno em estudo de maneira explícita (CÂMARA e CAMARGO, 2002). $\mathrm{O}$ uso de ferramentas de Geographic Information Systems (GIS) é bastante comum nesse contexto (FRANCISCO, 2010; GREGORI e LINK, 2006; ARANHA e FIGOLI, 2001).

A análise de rede especializou-se em "desenhar" as redes de modo a melhor comunicar centralidades ou relacionamentos entre seus elementos (BRANDES, KENIS e WAGNER, 2003; FRUCHTERMAN e REINGOLD, 1991; KAMADA e KAWAI, 1989), geralmente em duas ou três dimensões. Essas redes "espacialmente representadas" tornam-se "georreferenciadas", ou seja, seus elementos (nós, arestas) adquirem caracterização espacial, o que habilita o uso de praticamente todo o ferramental da análise espacial.

O insight da integração das ferramentas GIS à análise de rede está na utilização de espaços multidimensionais para representar os elementos estudados, com base nos quais se obtêm medidas de posicionamento e proximidade entre os elementos. Com isso, dois objetos "próximos" são mais parecidos, ou mais associados, entre si do que dois objetos distantes - e 
essa é a "primeira lei da geografia", segundo Tobler (1970). Técnicas próprias do "mundo" das análises geográficas, utilizadas para interpolar dados espaciais, como modelos digitais de terreno ou superfície (MDS), agrupamentos espaciais, densidade de padrões de pontos e correlação espacial (DIGGLE, 1983; RIPPLEY, 1981, 1988), podem ser apropriadas a espaços "não geográficos" (FRANCISCO, 2005). Autores, escolas ou periódicos mais influentes podem estar no topo de montanhas geradas por um modelo de superfície baseado na centralidade de grau de uma rede de colaboração (OLD, 2001).

Em suma, a análise bibliométrica adquire maior robustez e flexibilidade quando integrada à análise de redes e à análise geográfica. Implicitamente, muitos termos empregados pela análise de redes e pela análise bibliométrica tradicional foram importados da Geografia. Por exemplo, "distância geodésica" (BORGATTI, 2005; BRANDES, 2000; WEST, 1996) como a medida do número de arestas que separam dois nós da rede, e "cartografia temática" como a utilidade de percepção global de dados e análises bibliométricas por meio de mapas (KOBASHI e SANTOS, 2006, com base em estudos de TUFTE, 1983, e BERTIN, 1977).

De maneira geral, são cada vez mais comuns os artigos que utilizam essas técnicas para diferentes áreas no Brasil. A RAE abordou o tema em diversos artigos, com muitos autores dedicando-se à análise da produção acadêmica nacional (TONELLI e outros, 2003; LEAL, OLIVEIRA, SOLURI, 2003; ARKADER, 2003; CALDAS e TINOCO, 2004a; CARDOSO e outros, 2005; MENDONÇA NETO, RICCIO e SAKATA, 2009, por exemplo).

A própria RAE-eletrônica abordou esse tema algumas vezes. A pesquisa em gestão de Recursos Humanos nos anos 1990, objeto de artigo de Miguel Caldas e Tatiana Tinoco (2004a) na $R A E$, foi replicado por Barbosa (2004) e Mattos (2004) e treplicado por Caldas e Tinoco (2004b) na sexta edição da RAE-eletrônica, em interessante debate envolvendo críticas à própria metodologia em questão. Curiosamente, a tréplica de Caldas e Tinoco, de alguma forma, tangencia a integração de técnicas que discutimos parágrafos atrás - seu título resgata os "mapas e topógrafos" no uso das técnicas de análise bibliométrica.

Mais recentemente, ainda, Martins e outros (2010) empregaram técnicas de análise da rede social de pesquisadores no estudo da gestão de operações no Brasil, na $18^{\mathrm{a}}$ edição da RAE-eletrônica, estudo que inspirou, em parte, a construção deste artigo.

\section{METODOLOGIA EMPREGADA}

Este estudo consistiu na análise bibliométrica do acervo da RAE-eletrônica, de natureza descritiva e explicativa. Para tal, foi realizada a marcação dos textos de todos os artigos da revista (incluídos aí os editoriais, artigos, resenhas e pensatas), em padrão SciELO. Essa marcação consiste na identificação dos elementos que compõem o artigo: título, resumo, abstract, palavras-chave, autoria, corpo principal e referências bibliográficas.

Uma vez identificados os elementos, construiu-se uma estrutura de tabelas e matrizes que caracterizaram os artigos, as referências bibliográficas dos artigos, as palavras-chave dos artigos e as palavras (não estruturais) utilizadas nos títulos, nos resumos e no corpo principal dos textos.

O ambiente computacional foi criado na linguagem de programação (script interpretado) do programa $R$, em sua versão 2.12.2. $R$ é um software criado em ambiente livre para computação e programação estatística e geração de saídas gráficas, bastante extenso em funcionalidade e amplamente utilizado no meio acadêmico (R DEVELOPMENT CORE TEAM, 2011). Toda a leitura dos artigos já marcados (em formato texto), a identificação e a qualificação dos elementos de interesse foram feitas em $R$.

As extensões (packages) do $R$ utilizadas nessa implementação foram: (i) NETWORK 1.6, um conjunto de ferramentas para criação e modificação de objetos de rede (BUTTS, HANDCOCK, HUNTER, 2011; BUTTS, 2008), (ii) SNA (acrônimo de Social Network Analysis) 2.2-0, para análise e visualização de redes sociais (BUTTS, 2010), (iii) IGRAPH 0.5.5-2, para análise de grafos e redes complexas (CSARDI e NEPUSZ, 2006), (iv) MAPTOOLS 0.7-26, um conjunto de ferramentas para manipulação e leitura de dados geográficos (LEWIN-KOH e BIVAND, 2009) e (v) SPATSTAT (Spatial Statistics) 1.17-0 para a análise da densidade geográfica de pontos das redes (BADDELEY e TURNER, 2005).

Foram utilizadas as ferramentas geográficas Arcview GIS ${ }^{\circledast} 3.2$ e ArcGIS $^{\circledast}$ 9.3, com suas extensões Spatial Analyst 1.1, 3D Analyst 1.0 e ESRI ${ }^{\circledast}$ ArcSce- $^{-}$ ne ${ }^{\mathrm{TM}} 1.0$, para a visualização e análise de dados geográficos e a geração das superfícies de densidade e centralidade das redes. Adicionalmente, foi utilizada a ferramenta Wordle ${ }^{\mathrm{TM}}$ para a construção das nuvens de palavras, conceito que será oportunamente definido no decorrer deste artigo. 


\section{O ACERVO DA RAE-ELETRÔNICA: AUTORIA E AFILIAÇÃO}

O universo da pesquisa foi o acervo completo da $R A E-$ eletrônica, editada de modo independente de 2002 a 2010, em 18 edições, perfazendo um total de 222 artigos (considerando sete pensatas e 25 resenhas) e 18 editoriais. Em média, 13,3 artigos por edição.

Suas seções contemplam, ao longo desse período, diversos fóruns - de estudos críticos em administração (em 2004), de teoria institucional (em 2005), de gestão no
Brasil (em 2005), de novos modelos organizacionais (em 2006), de sociologia econômica (em 2007) e de gestão de operações (em 2010). Ocorreram também diversas seçõesprêmios - Prêmio de Gestão Empresarial (em 2002) e dois Prêmios PWC de Inovação em Gestão (em 2002 e 2003). No total, 29 artigos em fóruns e 17 em seções-prêmios.

A partir da sétima edição, em 2005, as seções foram agrupadas e classificadas como "Artigos", simplesmente. Para a finalidade das análises deste estudo, optou-se por reclassificar os 76 artigos nessa situação, incorporando também os fóruns, seções-prêmios, pensatas e resenhas em grupos temáticos. A Tabela 1 traz a

\section{Tabela 1 - Número de artigos por seção da RAE-eletrônica de 2002 a 2010}

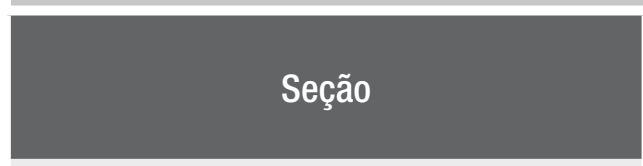

\section{Número de \\ artigos}

Editorial

18

Administração Hospitalar

Administração Pública

Ciência e Tecnologia

Controle Gerencial

Economia

Ensino e Pesquisa em Administração

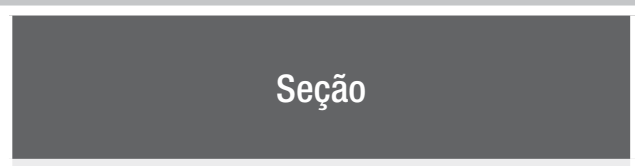

Número de

artigos

Finanças

15

Gestão da Informação

Gestão de Operações e Logística

Gestão de Pessoas

Gestão de Tecnologia e Inovação

Gestão Internacional

Gestão Socioambiental

Marketing

Organizações

42 
classificação final adotada dos 240 artigos do acervo.

O número médio de artigos por edição diminuiu ao longo do período. Por consequência, o número médio de autores por edição também caiu. Porém, a quantidade média de autores por artigo aumentou ao longo do período, o que compensou e superou a queda no número de artigos por edição, conforme mostram o Gráfico 1 e a Tabela 2.
O aumento na colaboração entre autores notado na história do acervo da RAE-eletrônica está de acordo com o que é apontado pela literatura para diversos campos científicos (MARTINS e outros, 2010; MELLO, CRUBELATE e ROSSONI, 2009). A média de autores por artigo de todo o acervo é 1,96.

Os 222 artigos da RAE-eletrônica (excluídos os 18 editoriais) são de 388 diferentes autores, sendo que a

\section{Gráfico 1 - Média de autores por artigo da RAE-eletrônica de 2002 a 2010}

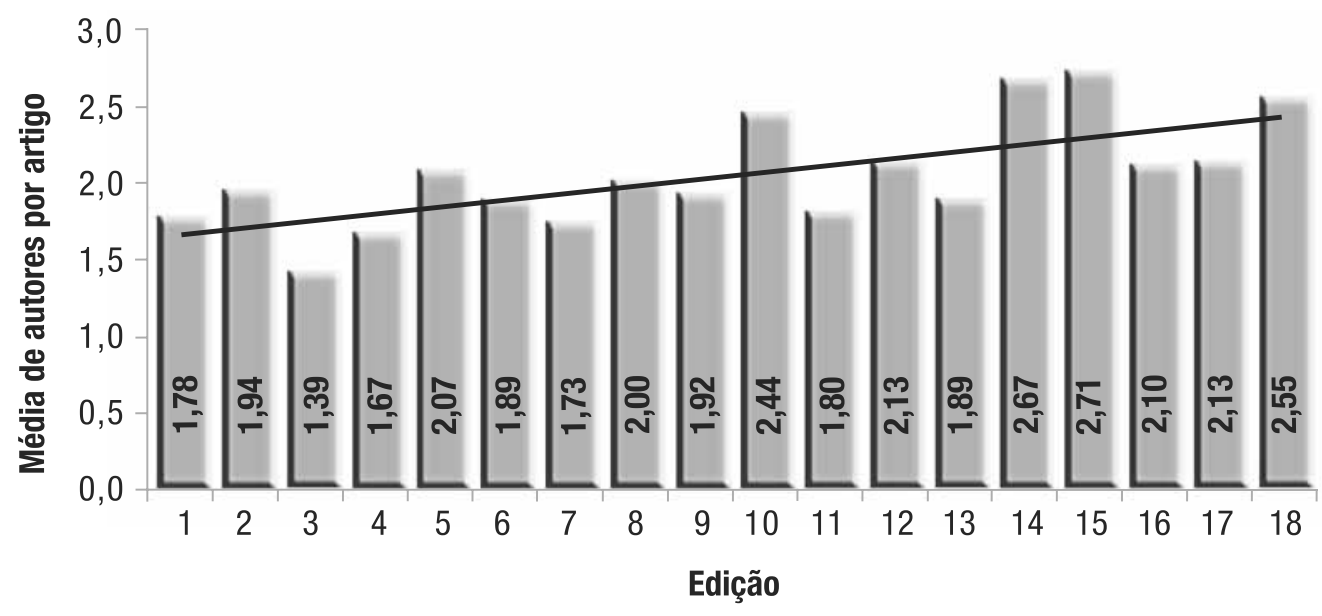

Tabela 2 - Número de artigos e autores por edição da RAE-eletrônica de 2002 a 2010

\begin{tabular}{|l|l|l|l|l|l|l|l|l|l|l|l|l|l|l|l|l|l|l|}
\hline Edição & $\mathbf{1}$ & $\mathbf{2}$ & $\mathbf{3}$ & $\mathbf{4}$ & $\mathbf{5}$ & $\mathbf{6}$ & $\mathbf{7}$ & $\mathbf{8}$ & $\mathbf{9}$ & $\mathbf{1 0}$ & $\mathbf{1 1}$ & $\mathbf{1 2}$ & $\mathbf{1 3}$ & $\mathbf{1 4}$ & $\mathbf{1 5}$ & $\mathbf{1 6}$ & $\mathbf{1 7}$ & $\mathbf{1 8}$ \\
\hline \# Artigos & 18 & 17 & 23 & 15 & 14 & 18 & 15 & 9 & 12 & 9 & 10 & 8 & 9 & 9 & 7 & 10 & 8 & 11 \\
\hline \# Autores & 32 & 33 & 32 & 25 & 29 & 34 & 26 & 18 & 23 & 22 & 18 & 17 & 17 & 24 & 19 & 21 & 17 & 28 \\
\hline
\end{tabular}

Nota: Desconsiderados os 18 editoriais. 
grande maioria (352) escreveu apenas um artigo. Outros 29 foram autores de dois artigos, e os sete autores descritos na Tabela 3 foram responsáveis por três ou mais artigos do acervo da RAE-eletrônica. O predomínio de autores com autoria única no acervo (90,7\% do total) está de acordo com o que foi observado por diversos autores em vários subcampos da Administração (MENDONÇA NETO, RICCIO e SAKATA, 2009; LEITE
FILHO, 2006; CARDOSO e outros, 2005; CALDAS e TINOCO, 2004a, entre outros), apesar da curta existência independente da RAE-eletrônica.

Na descrição de número de autores por artigo, 106 artigos são de apenas um autor, 80 em coautoria de dois autores, e 54 são escritos por três ou mais, como apresenta o Gráfico 2.

Optou-se por construir a rede (1-mode) de

\section{Tabela 3 - Autores com maior número de artigos na RAE-eletrônica de 2002 a 2010}

\section{Nome do autor}

Artigos escritos

MASCARENHAS, André Ofenhejm

VASCONCELOS, Flávio Carvalho de

VASCONCELOS, Isabella Freitas Gouveia de

BITENCOURT, Cláudia Cristina

FREITAS, Henrique Mello Rodrigues de

FREITAS, Maria Ester de

\section{Gráfico 2 - Número de autores por artigo da RAE-eletrônica de 2002 a 2010}

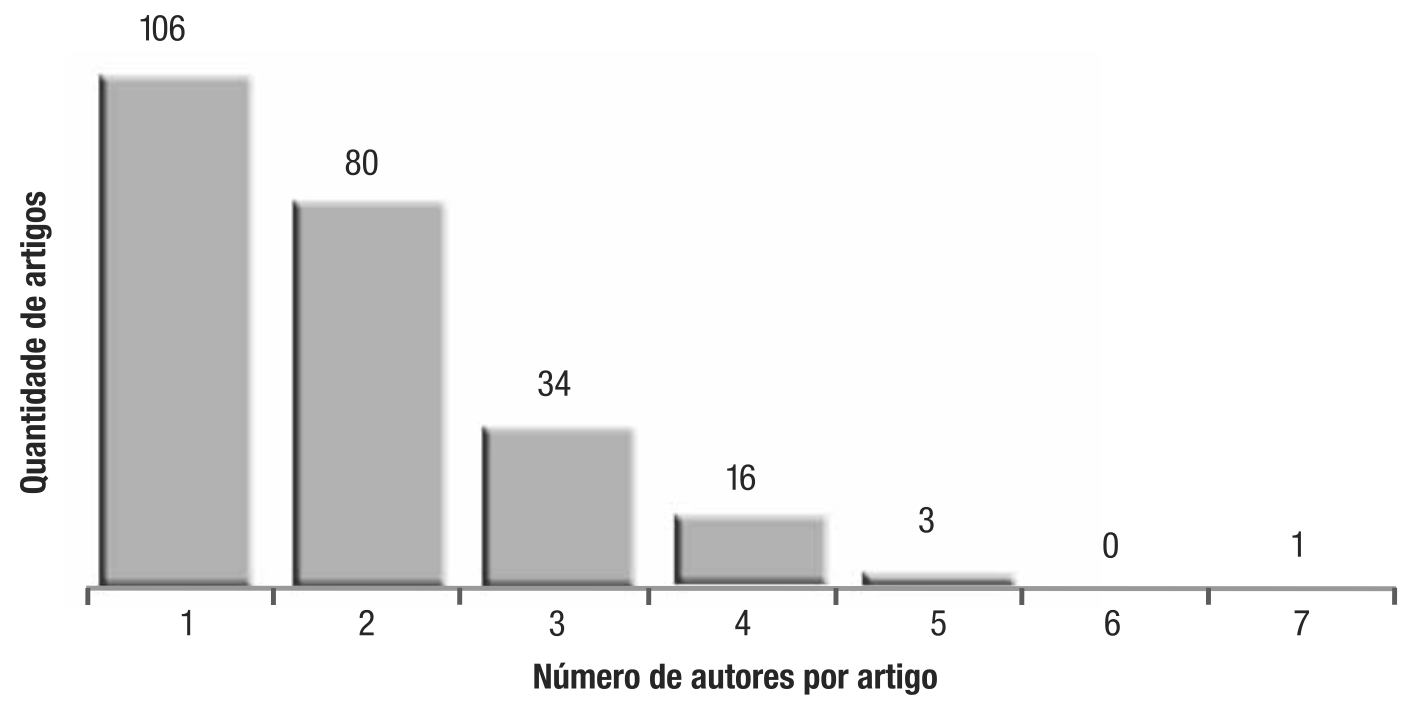


coautorias do acervo da RAE-eletrônica, considerando os 222 artigos (editoriais desprezados nessa análise). Pelo ecletismo de temas que a Administração abarca, completamente refletida na $R A E \mathrm{e}$ na RAE-eletrônica, e principalmente pelo pequeno número de artigos analisado, a rede mostrouse altamente desconectada. Desconsiderando os 74 autores que escreveram isoladamente seus 74 artigos, a rede apresenta 110 componentes, conforme a Figura 1.
Os nós da rede de coautorias da RAE-eletrônica são representados de acordo com o número de artigos de cada autor. Seis dos sete autores com três ou mais artigos estão representados e especialmente denominados na rede. As arestas estão simbolizadas de acordo com o número de coautorias entre seus pares, em diferentes artigos. Dessa forma, artigos de mais de dois autores são representados por mais de uma aresta na rede (uma para cada parceria entre dois autores). Nota-se o grande predomínio de par-

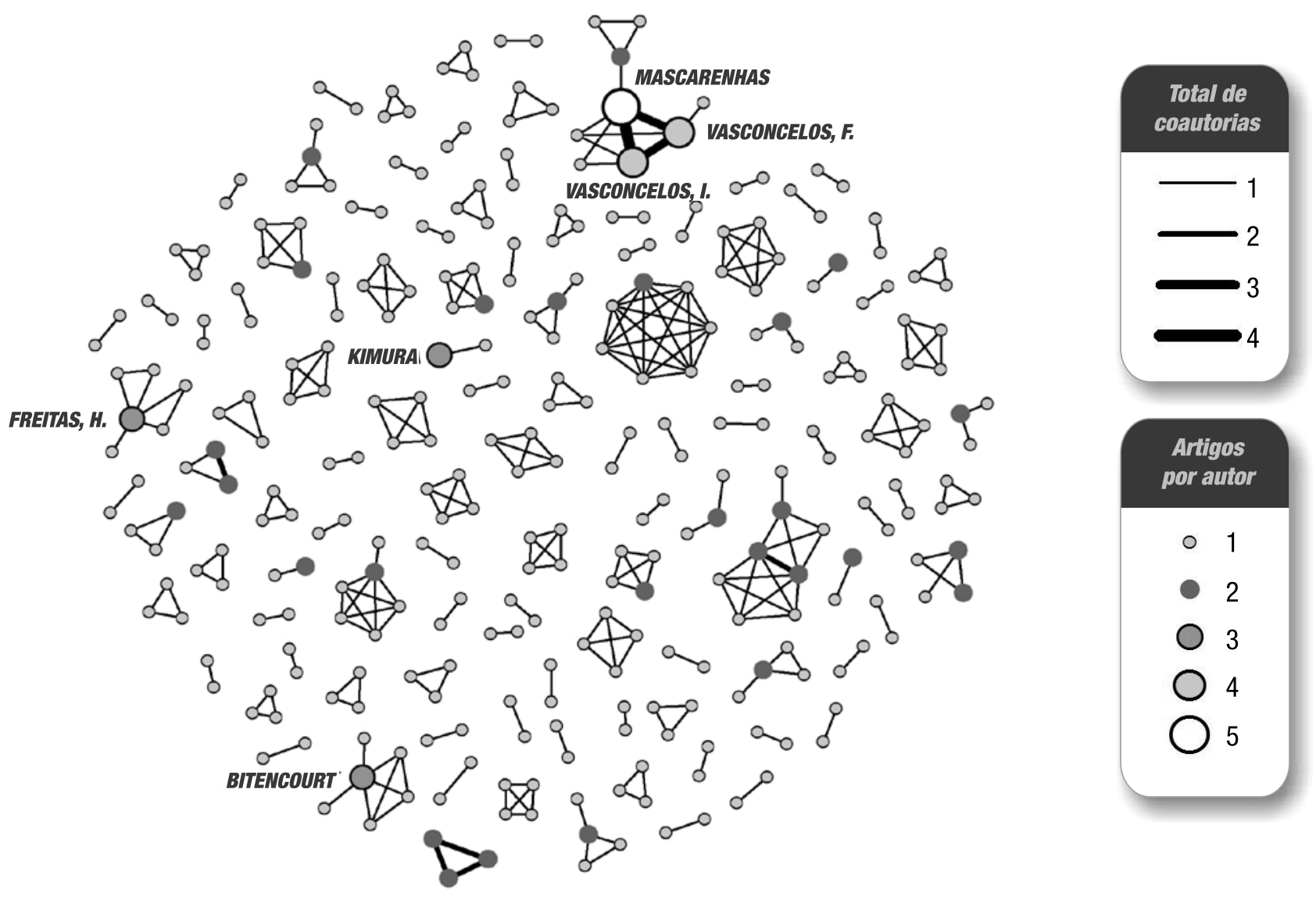


cerias que se estabeleceram para um único artigo apenas oito das 316 arestas da rede representam dois ou mais artigos em coautoria.

O Gráfico 3 traz a quantidade de componentes com diferentes números de autores. A rede de coautorias permite observarmos que a grande quantidade de componentes com dois, três ou quatro autores é resultante de apenas um artigo escrito em parceria pelos membros dessas componentes, o que apontam os menores nós da rede. Os dois principais componentes dessa rede, conforme a Figura 2, apresentam nove e oito autores, e correspondem a oito e três artigos, respectivamente. Em outras palavras, os nove autores em destaque no componente à esquerda da Figura 2 estabeleceram suas parcerias por meio de oito artigos da RAE-eletrônica.

\section{GRÁFICO 3 - Quantidade de componentes com diferentes números de autores da rede de coautorias do acervo da RAE-eletrônica de 2002 a 2010}

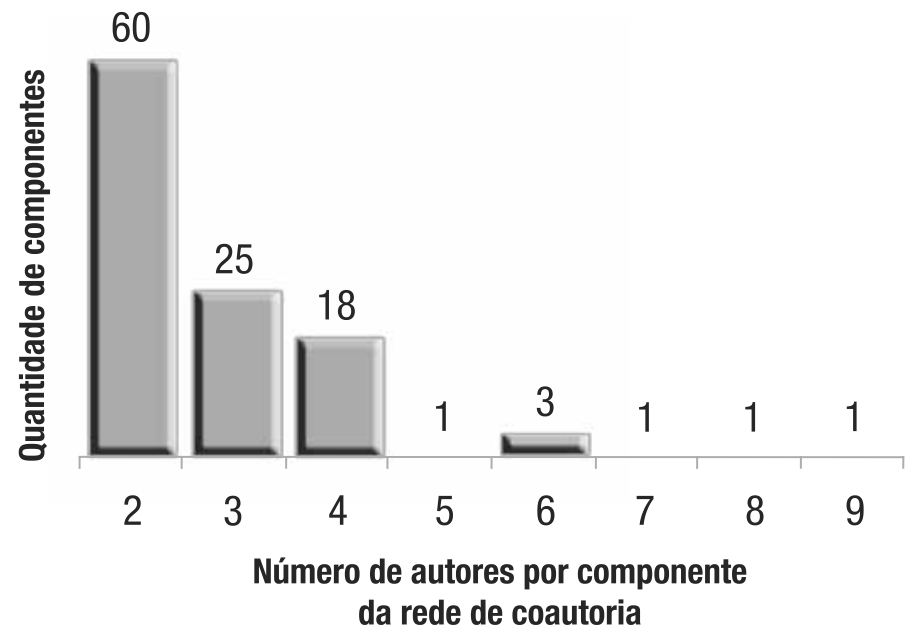

\section{Figura 2 - Dois principais componentes da rede de coautoria} da RAE-eletrônica de 2002 a 2010

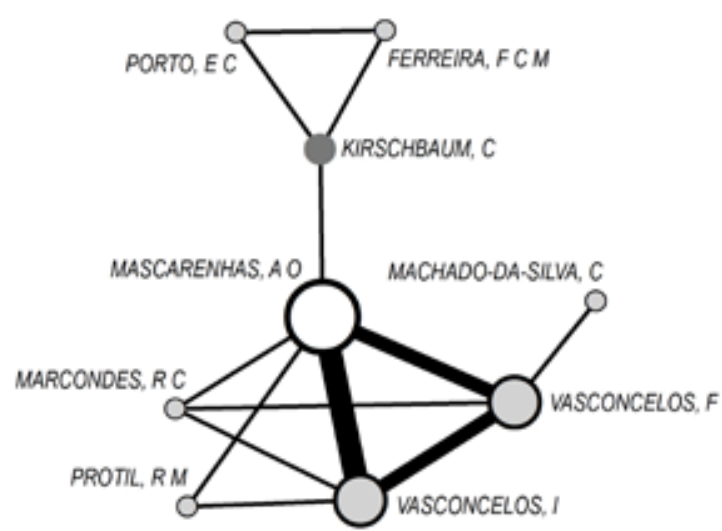

Número de artigos desse componente: 8

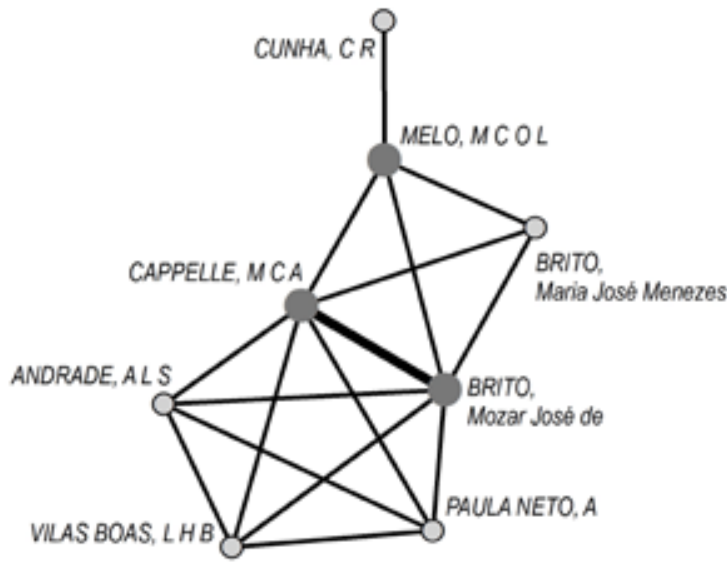

Número de artigos desse componente: $\mathbf{3}$
Artigos

por Autor

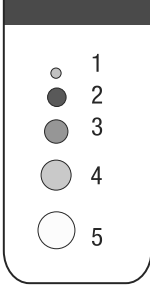

Total de

Coautorias

$\aleph 1$

$\widehat{N} 2$

N ${ }_{4}^{3}$ 
Esses componentes são grupos altamente coesos. Algumas análises realizadas mostraram que esses componentes apresentam alta densidade de nós $(36,1 \%$ e $57,1 \%$ ), definida pela quantidade de arestas existentes em relação às arestas possíveis de um componente (ACEDO e outros, 2006; HANNEMAN e RIDDLE, 2005; WASSERMAN e FAUST, 1994) - uma medida de intensidade de cooperação entre os autores (MELLO, CRUBELLATE e ROSSONI, 2010). Esses componentes apresentam, ainda, baixa distância média entre seus nós (2,02 e 1,54, respectivamente) e alta transitividade, ou coeficiente de agrupamento (77,6\% e 72,3\%), que consiste no número de ligações entre os vizinhos imediatos de um nó em comparação ao número máximo de laços que possam existir (WATTS e STROGATZ, 1998; WATTS, 1999). Redes densas diferenciam-se das aleatórias por apresentarem baixas distâncias entre seus nós e altos coeficientes de agrupamento, o que confere baixa necessidade de nós intermediários para que se dê o fluxo da informação (MELLO, CRUBELLATE, ROSSONI, 2010).

Os 222 artigos são de autores pertencentes a 122 afiliações (escolas, instituições públicas ou empresas privadas). Os autores são, na maioria, pertencentes a instituições acadêmicas - apenas Banco Central, BNDES, Fundação Abrinq, Fundação CPqD, IPEN e Nokia Siemens são exceções a essa regra, com autoria ou coautoria em seis artigos do acervo.

Das 117 instituições acadêmicas, 30 são estrangeiras, situadas nos EUA (nove instituições), Reino Unido (sete), Portugal (cinco), Canadá (três), França (três), Austrália (uma), Espanha (uma) e Itália (uma). Vale notar a preferência pelas parcerias internacionais com a Europa e América do Norte, e a ausência de instituições não brasileiras da América Latina.

A autoria internacional deu-se preferencialmente em coautoria com instituições brasileiras - isso ocorreu em 16 dos 28 artigos publicados. Dos 12 restantes, 11 são de autores de uma única instituição internacional.

Entre as 122 instituições, 24 publicaram três ou mais artigos e respondem por 187 dos 222 artigos do acervo $(84,2 \%)$. Os principais destaques são a FGVEAESP, com 69 artigos, a USP (considerando em conjunto as faculdades da USP baseadas em São Paulo: FEA-USP, POLI-USP, FFLCH-USP e EACH-USP), com 23, e a UFRGS, com 20. Outras 16 instituições tiveram autoria em dois artigos, e 82, em apenas um. A

\section{Tabela 4 - Instituições com mais autores dos artigos da RAE-eletrônica de 2002 a 2010}

\begin{tabular}{|l|r|}
\hline & \multicolumn{1}{|c|}{$\begin{array}{c}\text { Total de } \\
\text { artigos }\end{array}$} \\
\hline FGV-EAESP & 69 \\
\hline USP & 23 \\
\hline UFRGS & 20 \\
\hline UFPR & 13 \\
\hline UFMG & 12 \\
\hline UFRJ & 10 \\
\hline Unisinos & 9 \\
\hline UFSC & 8 \\
\hline Unicamp & 8 \\
\hline UNB & 7 \\
\hline PUC-RJ & 6 \\
\hline PUC-SP & 6 \\
\hline
\end{tabular}

\begin{tabular}{|c|c|}
\hline Instituição & $\begin{array}{l}\text { Total de } \\
\text { artigos }\end{array}$ \\
\hline UEM & 6 \\
\hline FGV-EBAPE & 5 \\
\hline Mackenzie & 5 \\
\hline PUC-MG & 5 \\
\hline UFLA & 4 \\
\hline UFPE & 4 \\
\hline USP São Carlos & 4 \\
\hline Insper & 3 \\
\hline PUC-PR & 3 \\
\hline Ufscar & 3 \\
\hline UNIV-Paris (França) & 3 \\
\hline Univali & 3 \\
\hline
\end{tabular}


Tabela 4 traz a lista de instituições com pelo menos três artigos publicados.

A grande maioria dos artigos foi escrita por apenas autores pertencentes a uma única instituição 129 deles. Artigos de autores de duas instituições correspondem a 66, e 27 de três ou mais, conforme o Gráfico 4.
Para analisar as instituições mais influentes e relevantes no acervo da RAE-eletrônica, optamos por realizar análises da rede de colaboração entre instituições da RAE-eletrônica, conforme apresentado na Figura 3. Os nós estão simbolizados de acordo com a quantidade de artigos diferentes por instituição, e as arestas representam a quantidade de coautorias entre as instituições pares.

\section{Gráfico 4 - Número de instituições por artigo da RAE-eletrônica de 2002 a 2010}

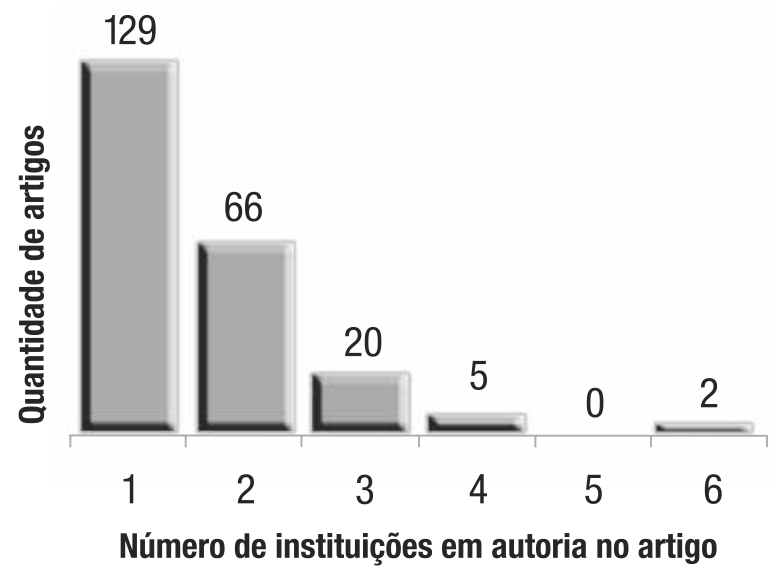

A rede apresenta conexão entre 102 de seus nós. Destaca-se um principal componente, com 86 nós interligados por 148 arestas (coautorias), com densidade de rede de $4,05 \%$, o que é uma medida alta relativa às redes de colaboração (MELLO, CRUBELATE e ROSSONI, 2009). Todas as instituições mais relevantes citadas na Tabela 2 fazem parte desse componente. As instituições com muitos artigos apresentam também alta centralidade de grau (número de arestas do nó), o que indica a grande preferência por coautorias para as instituições mais frequentes no acervo. Um componente com quatro afiliações (BNDES, Universidade de Aveiro [Portugal], Universidade Nova de Lisboa [Portugal] e UERJ), dois componentes com três afiliações interligadas, três com duas, e 20 nós isolados - instituições apenas com autoria isolada. Os strong cut-points, ou pontos de ar- ticulação, nós cuja remoção traria um aumento no número de componentes da rede (BORGATTI, EVERETT e FREEMAN, 2002), ocupam posições-chave na rede e estão nomeados na Figura 3.

A rede completa de colaboração entre instituições da RAE-eletrônica apresenta 161 laços, ligando 122 nós, resultado de 93 artigos produzidos por autores de mais de uma instituição. Uma simples comparação histórica entre os 141 artigos das primeiras nove edições (da primeira edição de 2002 à primeira edição de 2006) e os 81 artigos das últimas nove edições (da segunda edição de 2006 à segunda edição de 2010) permite observar que aumentou a proporção de artigos em coautoria por mais de uma instituição (de 48/141 $=34,0 \%$ para $45 / 81=55,5 \%)$, mesmo com a diminuição significativa no número de artigos no segundo período analisado. 


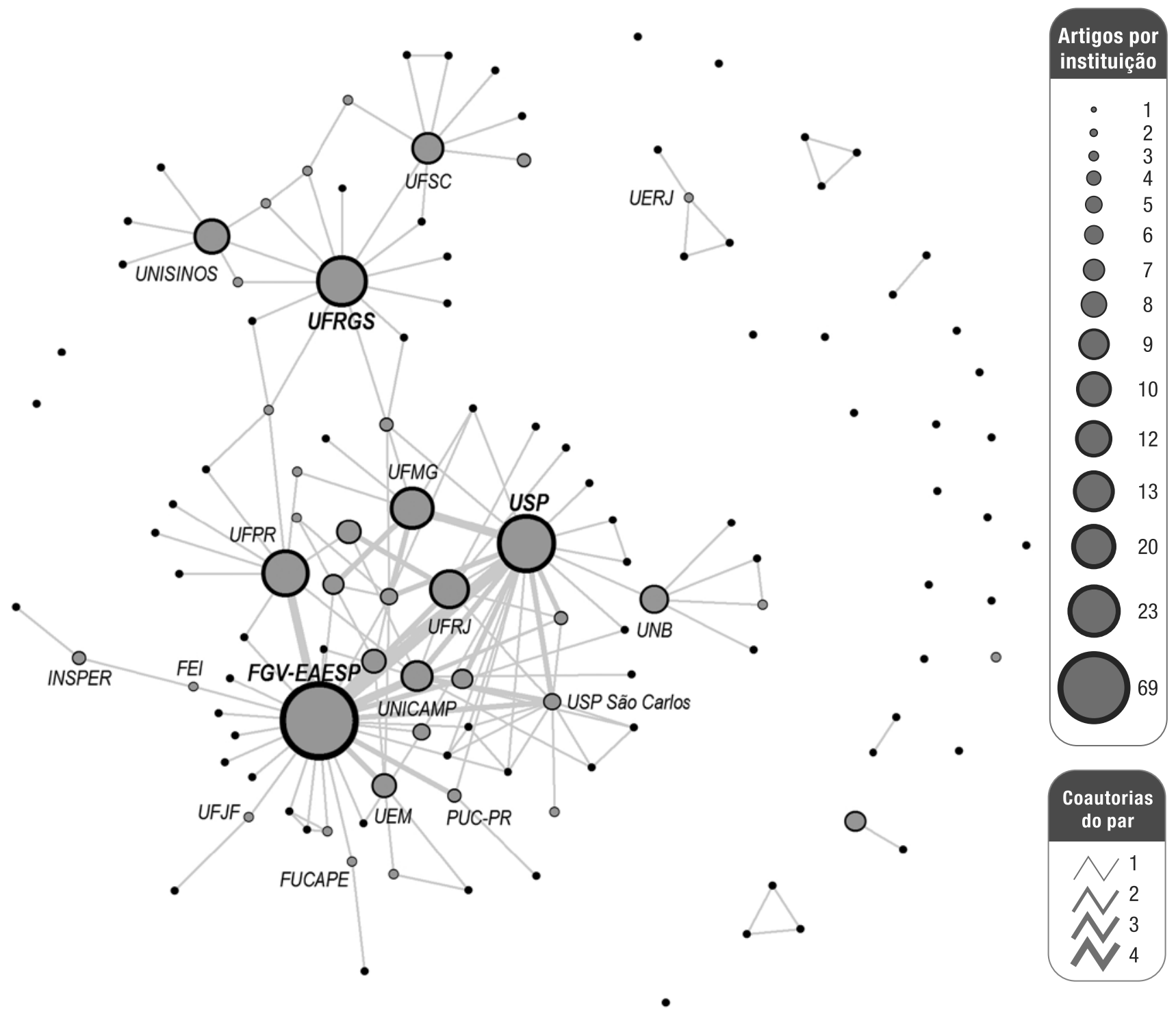

A Tabela 5 apresenta algumas medidas típicas de centralidade das instituições da rede - (i) centralidade de grau, ou número de laços de uma instituição com outras, determinada pela coautoria (WASSERMAN e FAUST, 1994), considerando a contabilização do total de parcerias (grau completo) e a diversidade de parcerias (grau simples); e (ii) centralidade de intermediação (betweenness centrality), medida da intermediação de uma instituição nas relações com as demais, servindo como ponte para a interação entre elas (HANNEMAN e RIDDLE, 2005). Optou-se em se trabalhar com a componente principal da rede para as análises de centralidade, conforme sugerem Newman (2001), Moody (2004) e Martins e outros (2010). As 23 instituições com três ou mais artigos no acervo estão representadas na tabela - apenas a FGV-EBAPE (com cinco artigos) não consta da tabela pela ausência de coautoria em seus cinco artigos para a RAE-eletrônica.

Destaca-se a força de três grandes nós (instituições) nessa rede: FGV-EAESP, USP e UFRGS, em número de artigos, em número de laços (centralidade de grau) e em intermediação, o que demonstra a importância des- 
sas três instituições para a disseminação e fluidez das informações divulgadas pela RAE-eletrônica durante suas 18 edições. Ocorre também alta associação entre número de artigos e número de colaborações (próprias e com outras instituições - 91,4\% de correlação) e entre número de artigos e centralidade de intermediação (75,5\% de correlação), o que já havia sido destacado por Martins e outros (2010) e diversos autores. Nota-se também a alta centralidade de intermediação da Uni- versité de Paris (UNIV-Paris), por ela estar localizada basicamente nos caminhos da rede entre a FGV-EAESP, a USP e a UFRGS.

Buscou-se construir uma representação geográfica tridimensional da rede pelo uso da técnica de análise espacial Triangulated Irregular Network (TIN), que consiste na construção de superfícies com base em uma rede de triângulos não sobrepostos (FOWLER, 1976; PEUCKER e outros, 1977). A Figura 4 apresenta a cons-

\section{Tabela 5 - Instituições com mais autores dos artigos da RAE-eletrônica de 2002 a 2010}

\begin{tabular}{|c|c|c|c|c|c|}
\hline Instituição & $\begin{array}{l}\text { Total de } \\
\text { artigos }\end{array}$ & $\begin{array}{c}\text { Artigos em } \\
\text { autocolaboração }\end{array}$ & $\begin{array}{c}\text { Grau } \\
\text { (completo) }\end{array}$ & $\begin{array}{c}\text { Grau } \\
\text { (simples) }\end{array}$ & Intermediação \\
\hline FGV-EAESP & 69 & 9 & 44 & 30 & 1416,4 \\
\hline USP & 23 & 5 & 31 & 21 & 1191,1 \\
\hline UFRGS & 20 & 3 & 13 & 13 & 1388,9 \\
\hline UFPR & 13 & 2 & 12 & 10 & 554,8 \\
\hline UFMG & 12 & 2 & 11 & 7 & 134,3 \\
\hline UFRJ & 10 & 2 & 10 & 8 & 270,4 \\
\hline Unisinos & 9 & 0 & 6 & 6 & 249,5 \\
\hline UFSC & 8 & 1 & 8 & 8 & 447,3 \\
\hline Unicamp & 8 & 1 & 15 & 11 & 341,7 \\
\hline UNB & 7 & 2 & 5 & 5 & 329,0 \\
\hline PUC-RJ & 6 & 1 & 4 & 3 & 0,0 \\
\hline PUC-SP & 6 & 2 & 7 & 5 & 79,6 \\
\hline UEM & 6 & 1 & 6 & 5 & 166,0 \\
\hline Mackenzie & 5 & 1 & 5 & 3 & 3,5 \\
\hline PUC-MG & 5 & 1 & 6 & 5 & 43,4 \\
\hline UFLA & 4 & 2 & 11 & 9 & 666,5 \\
\hline UFPE & 4 & 0 & 3 & 3 & 67,6 \\
\hline USP São Carlos & 4 & 2 & 14 & 11 & 163,2 \\
\hline Insper & 3 & 0 & 2 & 2 & 84,0 \\
\hline PUC-PR & 3 & 0 & 4 & 3 & 84,0 \\
\hline Ufscar & 3 & 1 & 6 & 5 & 87,6 \\
\hline Univali & 3 & 0 & 1 & 1 & 0,0 \\
\hline UNIV-Paris (FR) & 3 & 0 & 5 & 5 & 1138,2 \\
\hline
\end{tabular}

Nota: Descontados os editoriais dos artigos. 
trução da TIN com base na rede de colaboração entre instituições, utilizando a centralidade de grau (simples) de cada instituição como informação de elevação; essa análise permite que facilmente visualizemos a configuração da rede e seus atores mais relevantes em colaboração, e ressalta a importância e a influência da FGVEAESP, USP ou UFRGS no contexto da RAE-eletrônica.

Complementarmente, as instituições foram posicionadas no globo terrestre, baseando-se na localização geográfica de seu endereço. Para instituições com mais de um campus, optou-se por selecionar o campus com maior número de pesquisadores autores de artigos da RAE-eletrônica. Essa análise permitiu a verificação da alta concentração de instituições e de interligações (coautorias) nas regiões Sudeste e Sul do Brasil, com destaque para o Estado de São Paulo. O globo terrestre, destacando as coautorias envolvendo instituições estrangeiras, é também representado nos mapas da Figura 5. Analisando a densidade geográfica da distribuição espacial da rede de colaboração entre instituições, baseado na centralidade de intermediação de seus nós, destaca-se a região do município de São Paulo, que baseia 15 das 122 instituições.

A seguir, são apresentadas análises referentes às fontes bibliográficas dos artigos da RAE-eletrônica.

\section{O ACERVO DA RAE-ELETRÔNICA; REFERÊNCIAS BIBLIOGRÁFICAS}

Dos 222 artigos da RAE-eletrônica, 187 fizeram referência explícita ou implícita a outros artigos - as 35 restantes são resenhas (27), debates (três), pensatas (duas), apresentações de fóruns (duas) ou entrevista (uma). No total, 5.404 referências bibliográficas foram citadas. Cerca de 29 referências bibliográficas citadas por artigo, em média. Dessas, 5.028 (93,0\% do total) foram citadas por apenas um artigo, o que sinaliza $\mathrm{o}$ ecletismo e a vastidão de citações que a RAE-eletrônica apresentou nesse período. As 376 referências bibliográficas restantes foram citadas por dois a 19 artigos diferentes do acervo, conforme distribuição ilustrada no Gráfico 5. A Tabela 6 nomeia as 16 referências citadas cinco ou mais vezes pelos artigos da RAE-eletrônica.

Optou-se por considerar, nesta análise, versões traduzidas de obras como sendo a mesma, uma vez que o conteúdo da obra foi o real objeto analisado, e não suas diferentes edições ou versões, mesmo que haja significativa variação ao longo do tempo. Por essa razão, o autor R. K. Yin teve seu livro Case Study Research

\section{Figura 4 - Construção da triangulated irregular network para a rede de colaboração entre instituições da RAE-eletrônica de 2002 a 2010}

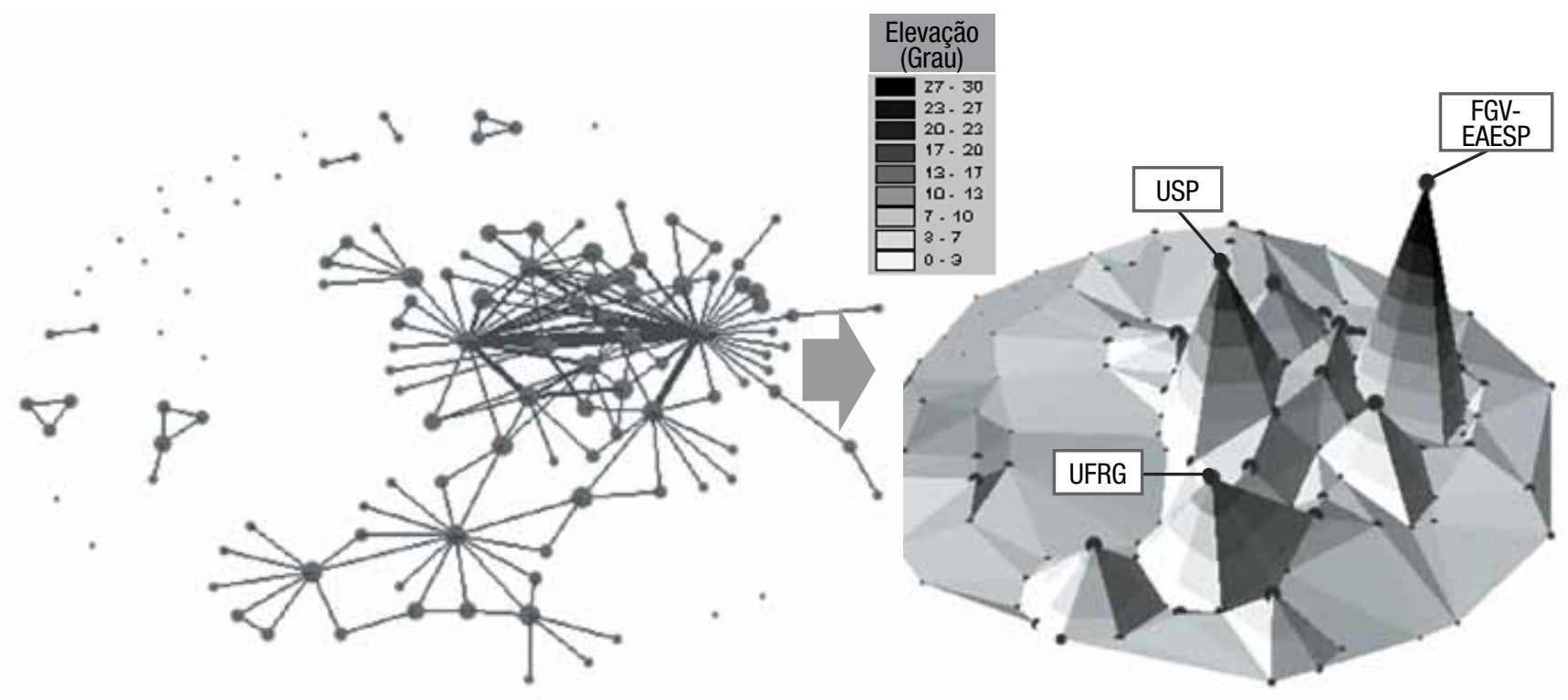

Rede de colaboração entre afiliações (planar)

Construção da Triangular Irregular Network (TIN) 
como o mais citado - 10 vezes uma versão em Inglês e nove vezes uma versão em Português.

Os mais citados pela RAE-eletrônica são autores internacionais de grande notoriedade nos campos da Administração, Sociologia e campos correlatos, o que é razoável e confirmado por outros estudos de citações (por exemplo, MACHADO-DA-SILVA, GUARIDO, ROSSONI, 2006a, 2006b).

Curiosamente, somente oito artigos da RAE-eletrônica foram citados por outros artigos da própria revista, principalmente em autocitação. O artigo "Impacto de Treinamento no Trabalho via Internet", das autoras T. Zerbini e G. Abbad, da oitava edição, foi citado por artigo da nona edição, escrito pelas próprias autoras em coautoria com R. S. Carvalho. O artigo "Pesquisa de Satisfação: Um Modelo para a Saúde", de G. S. Milan e G. Trez, da oitava edição, foi citado por dois artigos um deles de autoria de G. S. Milan. O artigo "Paradoxos Culturais na Gestão de Pessoas", de A. Mascarenhas, I. Vasconcelos e R. Protil, foi citado por artigo de I. Vasconcelos, A. Mascarenhas e F. Vasconcelos. Além desses, os artigos "Organizações Modernas e a Burocracia: Uma Afinidade Eletiva”, de F. R. N. Matos e A. C. Lima, da 11 $1^{\underline{a}}$ edição, "Paradoxos Organizacionais, Gestão de Pessoas e Tecnologia na Souza Cruz", de I. Vasconcelos e outros, da sexta edição, e a resenha "Negociação", de H. R. S. Tamashiro, da sexta edição, foram citados por artigos de outros autores.

\section{Figura 5 - Mapas da distribuição geográfica da rede de colaboração de coautoria entre instituições da RAE-eletrônica de 2002 a 2010: (topo esq.) rede de coautorias entre instituições brasileiras, (topo dir.) concentração de artigos por estado da federação, (base) rede de coautorias envolvendo instituições estrangeiras}

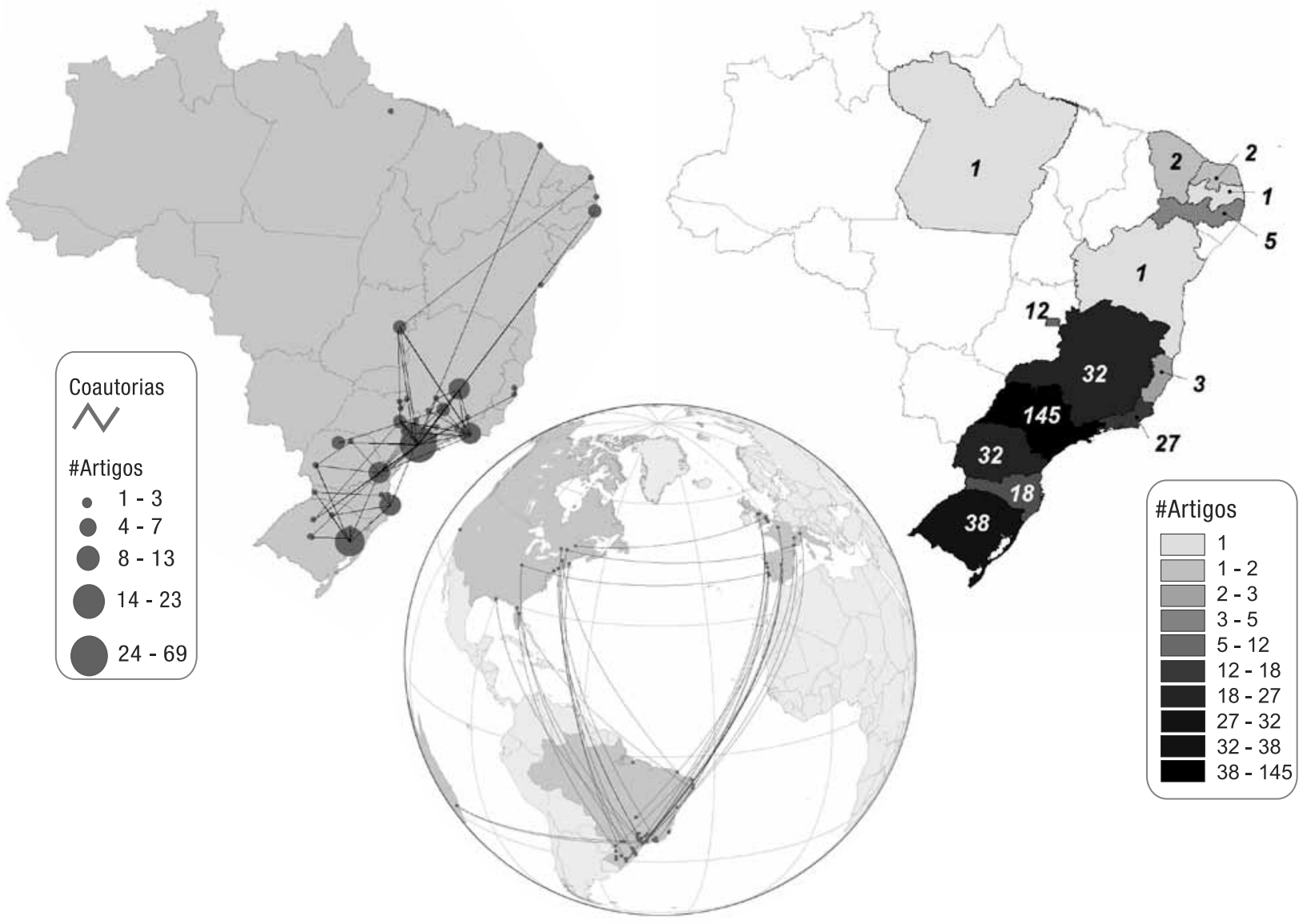


As 5.404 referências citadas foram escritas por 5.659 diferentes autores. A Tabela 7 a seguir mostra os autores com 15 ou mais citações, já descontadas as autorreferências. Caso o autor tenha uma obra citada por diferentes artigos, ou diferentes obras citadas por um mesmo artigo, ambas as situações são contabilizadas.

Além dos 22 autores listados na Tabela 7, outros 5.631 autores apresentaram 14 ou menos artigos citados.

\section{Gráfico 5 - Total de referências bibliográficas citadas por dois ou mais artigos}

da RAE-eletrônica de 2002 a 2010 RAE-eletrônica de 2002 a 2010

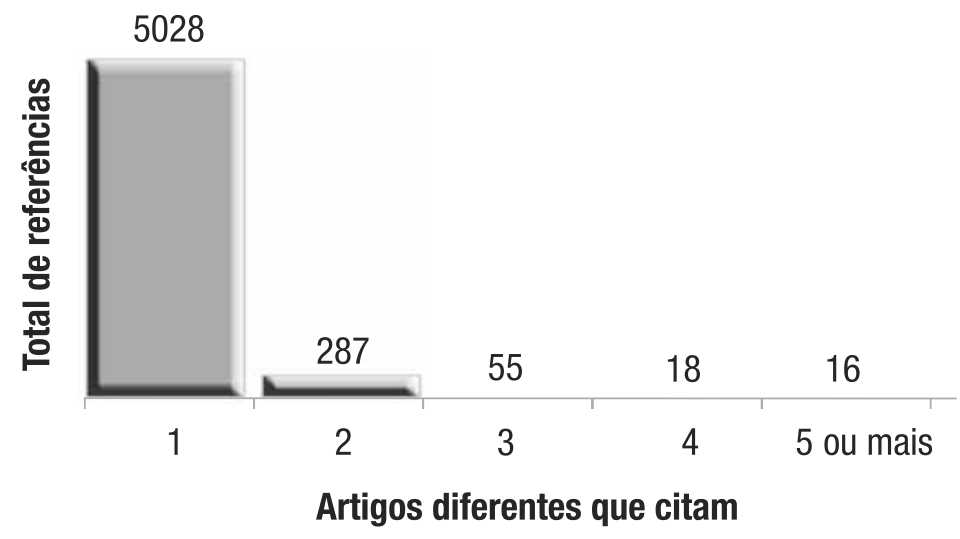

Tabela 6 - Referências bibliográficas citadas cinco ou mais vezes na RAE-eletrônica de 2002 a 2010

\begin{tabular}{|c|c|c|c|}
\hline Autores & Título & $\begin{array}{l}\text { Ano da primeira } \\
\text { edição citada }\end{array}$ & $\begin{array}{l}\text { Número de } \\
\text { citações }\end{array}$ \\
\hline YIN, R. K. & $\begin{array}{l}\text { Case Study Research - Design and Methods / Estudo de Caso } \\
\text { Planejamento e Métodos }\end{array}$ & 1994 & 19 \\
\hline HAIR JR, J. F. & Multivariate Data Analysis & 1998 & 18 \\
\hline BARDIN, L. & Análise de Conteúdo & 1977 & 10 \\
\hline CASTELLS M. & A Sociedade em Rede & 1999 & 9 \\
\hline $\begin{array}{l}\text { BERGER, P; LUCKMANN, T; } \\
\text { FERNANDES, F.D.S. }\end{array}$ & $\begin{array}{l}\text { A Construção Social da Realidade } \\
\text { Tratado de Sociologia do Conhecimento }\end{array}$ & 1976 & 8 \\
\hline MORGAN, G. & Imagens da Organização & 1996 & 7 \\
\hline $\begin{array}{l}\text { TABACHNICK, B. G; } \\
\text { FIDELL, L. S. }\end{array}$ & Using Multivariate Statistics & 2001 & 7 \\
\hline SENGE, P. M. & A Quinta Disciplina & 2000 & 6 \\
\hline PAGÈS, M. E OUTROS & $\begin{array}{l}0 \text { Poder das Organizações - A Dominação das Multinacionais } \\
\text { Sobre os Indivíduos }\end{array}$ & 1987 & 6 \\
\hline PORTER, M. E. & Vantagem Competitiva - Criando e Sustentando um Desempenho Superior & 1989 & 6 \\
\hline KOTLER, P. & $\begin{array}{l}\text { Administração de Marketing - Análise, Planejamento, } \\
\text { Implementação e Controle }\end{array}$ & 1991 & 5 \\
\hline KAHNEMAN, D; TVERSKY,A. & Prospect Theory - An Analysis of Decision Under Risk & 1979 & 5 \\
\hline BRAVERMAN, $\mathrm{H}$. & Trabalho e Capital Monopolista - A Degradação do Trabalho no Século XX & 1987 & 5 \\
\hline SCHEIN, E. H. & Organizational Culture and Leadership & 1996 & 5 \\
\hline ROESCH, S. M. A. & $\begin{array}{l}\text { Projetos de Estágio e de Pesquisa em Administração - Guia para Estágios, } \\
\text { Trabalhos de Conclusão, Dissertações e Estudos de Caso }\end{array}$ & 1999 & 5 \\
\hline BARNEY, J. B. & Firm Resources and Sustained Competitive Advantage & 1991 & 5 \\
\hline
\end{tabular}


A imensa maioria de autores (4.169, cerca de $73,7 \%$ do total) teve apenas um artigo citado. Outros 788 tiveram dois, e 284 tiveram três artigos citados.

As referências bibliográficas foram qualificadas conforme seu tipo: artigo de periódico, livro (ou capítulo de livro) e artigo de evento. Nota-se, no geral, predomínio das citações a livros ou capítulos de livros (51,5\%), com frequência um pouco superior à de artigos de periódicos $(42,2 \%)$. A menção a artigos de eventos é rara $(6,3 \%)$ e a outros tipos de referências (p.e., revistas não acadêmicas), irrelevante. A Tabela 8 mostra a distribuição dos tipos de citações para as principais seções da RAE-eletrônica, conforme reclassificação apresentada na Tabela 1.

Entre as 2.376 referências a periódicos, a preferência por periódicos internacionais é muito grande. A Tabela 9 apresenta os principais periódicos nacionais e internacionais com artigos referenciados pela RAE-eletrônica. À exceção da $R A E$, que é o pe- riódico mais citado, com 98 citações, os 10 principais periódicos mencionados são internacionais. A RAE-eletrônica é o quinto periódico nacional mais influente, com seus oito artigos citados, mesmo com uma existência independente curta de 18 edições - a partir da nona edição, iniciaram-se as autocitações.

Com relação à menção a artigos de eventos, a preferência pelos congressos da Anpad, em especial ao Enanpad, é altíssima. Das 363 referências a artigos de eventos, 175 (48,2\%) são de artigos do Enanpad, nove do Encontro de Marketing da ANPAD (EMA) e seis são do Encontro de Estudos em Estratégia (3Es), da ANPAD. Esses são os congressos mais citados e também alguns dos mais influentes no campo da Administração no Brasil.

A seção seguinte aborda os aspectos referentes ao conteúdo da RAE-eletrônica, por meio da análise das palavras, ou conceitos, mais frequentes e influentes dos artigos do acervo.

\section{Tabela 7 - Autores com 15 ou mais de 10 citações na RAE-eletrônica de 2002 a 2010}

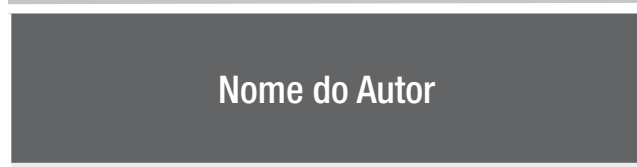

PORTER, M.

35

BORGES-ANDRADE, J.

MINTZBERG, H.

YIN, R.

POWELL,W.

ZEITHAML, V.

ENRIQUEZ, E.

FORNELL, C.

MEYER, J.

MORGAN, G.

CALDAS, M.

16 (1)
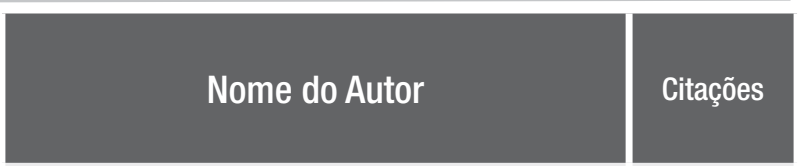

WEBER, M.

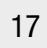

WILLIAMSON, 0.

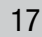

ARGYRIS, C.

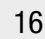

DIMAGGIO, P.

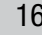

KAPLAN, $R$.

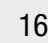

PRAHALAD, C.

SCOTT, W.

ANDERSON, R.

BAUDRILLARD, J.

MOTTA, F.

SIMON, H.

Nota: Números entre parênteses indicam o total de autorreferência dos autores. 


\section{ACERVO DA RAE-eletrônica: ANÁLISE DE CONTEÚDO}

Foram realizadas análises das palavras e conceitos mais mencionados nos artigos do acervo da RAE-eletrônica. As análises abordaram os títulos, as palavras-chave e os resumos dos artigos, e circunscreveram-se ao conteúdo em Português da revista.
Com relação às palavras-chave, geralmente são informadas de três a cinco por artigo. Dos 222 artigos, 172 explicitaram palavras-chave, totalizando 659 palavras diferentes. As 33 palavras-chave citadas três ou mais vezes estão na Tabela 10 .

Uma análise da rede de associação entre as palavras-chave foi realizada. Considerando duas palavraschave associadas, se elas foram palavras-chave de um mesmo artigo, a rede mostrou alto grau de associa-

\section{Tabela 8 - Tipos de referências bibliográficas mais citados, por seção,} da RAE-eletrônica de 2002 a 2010

\begin{tabular}{|c|c|c|c|c|c|}
\hline Seção & $\begin{array}{l}\text { Artigo de } \\
\text { periódico }\end{array}$ & $\begin{array}{l}\text { Livro ou } \\
\text { capítulo } \\
\text { de livro }\end{array}$ & $\begin{array}{c}\text { Paper de } \\
\text { evento }\end{array}$ & $\begin{array}{l}\text { Total de } \\
\text { artigos }\end{array}$ & $\begin{array}{c}\text { Total de referências } \\
\text { bibliográficas }\end{array}$ \\
\hline Administração Hospitalar & $44,3 \%$ & $53,4 \%$ & $2,3 \%$ & 4 & 135 \\
\hline Administração Pública & $31,4 \%$ & $66,2 \%$ & $2,4 \%$ & 9 & 219 \\
\hline Ciência e Tecnologia & $44,7 \%$ & $44,7 \%$ & $10,6 \%$ & 8 & 272 \\
\hline Contabilidade Gerencial & $52,9 \%$ & $39,7 \%$ & $7,4 \%$ & 2 & 70 \\
\hline Controle Gerencial & $33,3 \%$ & $65,8 \%$ & $0,9 \%$ & 4 & 115 \\
\hline Ensino e Pesquisa em Administração & $55,9 \%$ & $33,1 \%$ & $11,0 \%$ & 11 & 138 \\
\hline Estratégia & $45,4 \%$ & $48,6 \%$ & $6,0 \%$ & 20 & 553 \\
\hline Finanças & $56,4 \%$ & $36,1 \%$ & $7,5 \%$ & 15 & 497 \\
\hline Gestão da Informação & $39,0 \%$ & $53,8 \%$ & $7,3 \%$ & 14 & 414 \\
\hline Gestão de Operações e Logística & $52,5 \%$ & $44,8 \%$ & $2,8 \%$ & 18 & 380 \\
\hline Gestão de Pessoas & $28,7 \%$ & $66,2 \%$ & $5,0 \%$ & 26 & 781 \\
\hline Gestão de Tecnologia e Inovação & $31,2 \%$ & $61,1 \%$ & $7,6 \%$ & 4 & 161 \\
\hline Gestão Internacional & $54,4 \%$ & $45,6 \%$ & $0,0 \%$ & 6 & 109 \\
\hline Gestão Sócioambiental & $34,4 \%$ & $59,7 \%$ & $5,9 \%$ & 9 & 262 \\
\hline Marketing & $54,7 \%$ & $36,5 \%$ & $8,8 \%$ & 25 & 743 \\
\hline Organizações & $35,3 \%$ & $58,1 \%$ & $6,6 \%$ & 42 & 1095 \\
\hline TOTAL GERAL & $42,3 \%$ & $51,5 \%$ & $6,3 \%$ & $217^{*}$ & 5944 \\
\hline
\end{tabular}

*: 5 artigos da seção Economia não citaram referências bibliográficas e, por esta razão, não constam da tabela. 
ção entre seus elementos. A Figura 6 a seguir traz a topologia dessa rede (1-mode), apresentando apenas as 78 palavras-chave citadas pelo menos duas vezes.

Sessenta e nove das 78 palavras-chave estão conectadas, contendo 32 das 33 palavras-chave mais frequentes da Tabela 10. Notam-se termos como "estratégia", "tecnologia da informação" e "mudança organizacional" ocupando posições centrais na rede.

A avaliação da centralidade de intermediação e número de laços (grau) do componente principal da rede de palavras-chave do acervo da RAE-eletrônica (considerando apenas as citadas duas ou mais vezes) mostrou que os termos "mudança organizacional" e "tecnologia da informação" ocupam posições e influências centrais no fluxo informacional temático do acervo, conforme a Tabela 11. Essas duas também estão entre as palavras-chave mais frequentes, apresentadas anteriormente na Tabela 10 .
Curiosamente, termos como "marketing", "desenvolvimento", "desempenho", "gestão", entre outros, aparecem com frequências baixas relativas a outros termos menos usuais. Isso se dá devido ao uso de termos mais específicos como palavras-chave referentes a esses conceitos. O termo "marketing" é, na verdade, mencionado nove vezes - quatro diretamente e cinco por meio das especializações "marketing de serviços", "marketing de varejo", "marketing educacional", "marketing hospitalar" e "marketing social". O mesmo fenômeno ocorreu com termos como "organizações" e "gestão", entre outros. Como o uso genérico do conceito "tecnologia da informação" é mais frequente que suas subclassificações, esse termo tornou-se o mais frequente entre as palavras-chave de todo o acervo.

Considerando a frequência de palavras isoladas, de modo a fortalecer a ocorrência de palavras pro-

\section{Tabela 9 - Periódicos mais citados da RAE-eletrônica de 2002 a 2010}

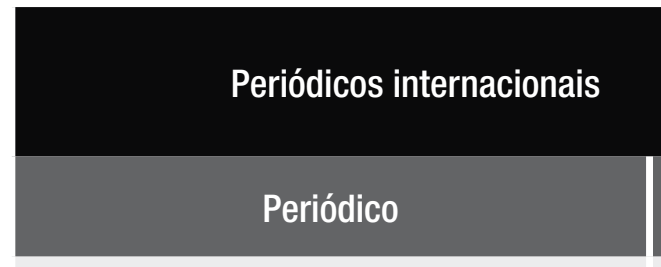

The Academy of Management Review

\begin{tabular}{|l|l|}
\hline Journal of Marketing & 62 \\
\hline Strategic Management Journal & 60 \\
\hline Harvard Business Review & 57 \\
\hline Administrative Science Quarterly & 52 \\
\hline Journal of Consumer Research & 46 \\
\hline Journal of Finance & 41 \\
\hline Journal of Marketing Research & 38 \\
\hline Journal of Financial Economics & 27 \\
\hline Organization Science & 25 \\
\hline Organization Studies & 25 \\
\hline Journal of Operations Management & 22 \\
\hline American Journal of Sociology & 20 \\
\hline
\end{tabular}

Citações
80

\section{Periódicos nacionais}

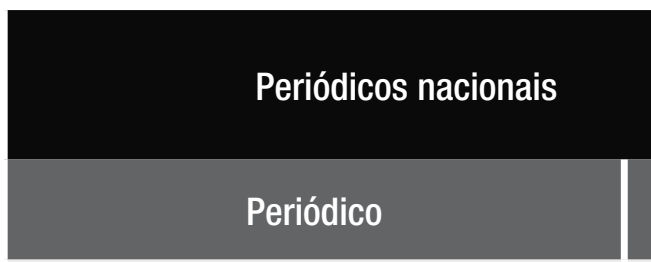

Citações

$R A E$ - revista de administração de empresas

RAC - Revista de Administração Contemporânea

RAP - Revista de Administração Pública

RAUSP

RAE-eletrônica

Revista Exame

Revista do BNDES

Educação e Sociedade

Ciência Saúde Coletiva

Folha de São Paulo

Gazeta Mercantil

HSM Management

Valor Econômico
11

26

13

8

8

7

6

5

5

5

5

5 
venientes de termos compostos, termos mais tradicionais da Administração sobrepõem-se, conforme a nuvem de palavras e a tabela da Figura 7. A nu- vem de texto, ou nuvem de palavras, é uma forma de visualização de dados linguísticos que mostra a frequência com que as palavras aparecem em de-

\section{Tabela 10 - Palavras-chave mais citadas nos artigos da RAE-eletrônica de 2002 a 2010}

\begin{tabular}{|l|r|}
\hline Palavra-chave & $\begin{array}{r}\text { Total de } \\
\text { citações }\end{array}$ \\
\hline Tecnologia da Informação & 8 \\
\hline Comportamento do Consumidor & 6 \\
\hline Estratégia & 6 \\
\hline Mudança Organizacional & 6 \\
\hline Cultura Organizacional & 5 \\
\hline Gestão de Pessoas & 5 \\
\hline Internet & 5 \\
\hline Relações de Trabalho & 5 \\
\hline Aprendizagem & 4 \\
\hline Aprendizagem Organizacional & 4 \\
\hline Comércio Eletrônico & 4 \\
\hline Competitividade & 4 \\
\hline Cooperação & 4 \\
\hline Inovação & 4 \\
\hline Marketing & 4 \\
\hline Tomada de Decisão & 4 \\
\hline
\end{tabular}

\section{Palavra-chave}

Total de

citações

Cadeia de Suprimentos
Decisão

Desempenho Empresarial $\quad 3$ Estrutura Organizacional 3

Ética

Etnografia

Gestão Ambiental

Paradoxos Organizacionais

Planejamento

Políticas Públicas

Representações Sociais

Responsabilidade Social Corporativa

Transferência de Conhecimento

Tributação

Vantagem Competitiva
3

3

3

3

3

3

3

3

3

3

3

3

Figura 6 - Rede de palavras-chave dos artigos da RAE-eletrônica de 2002 a 2010

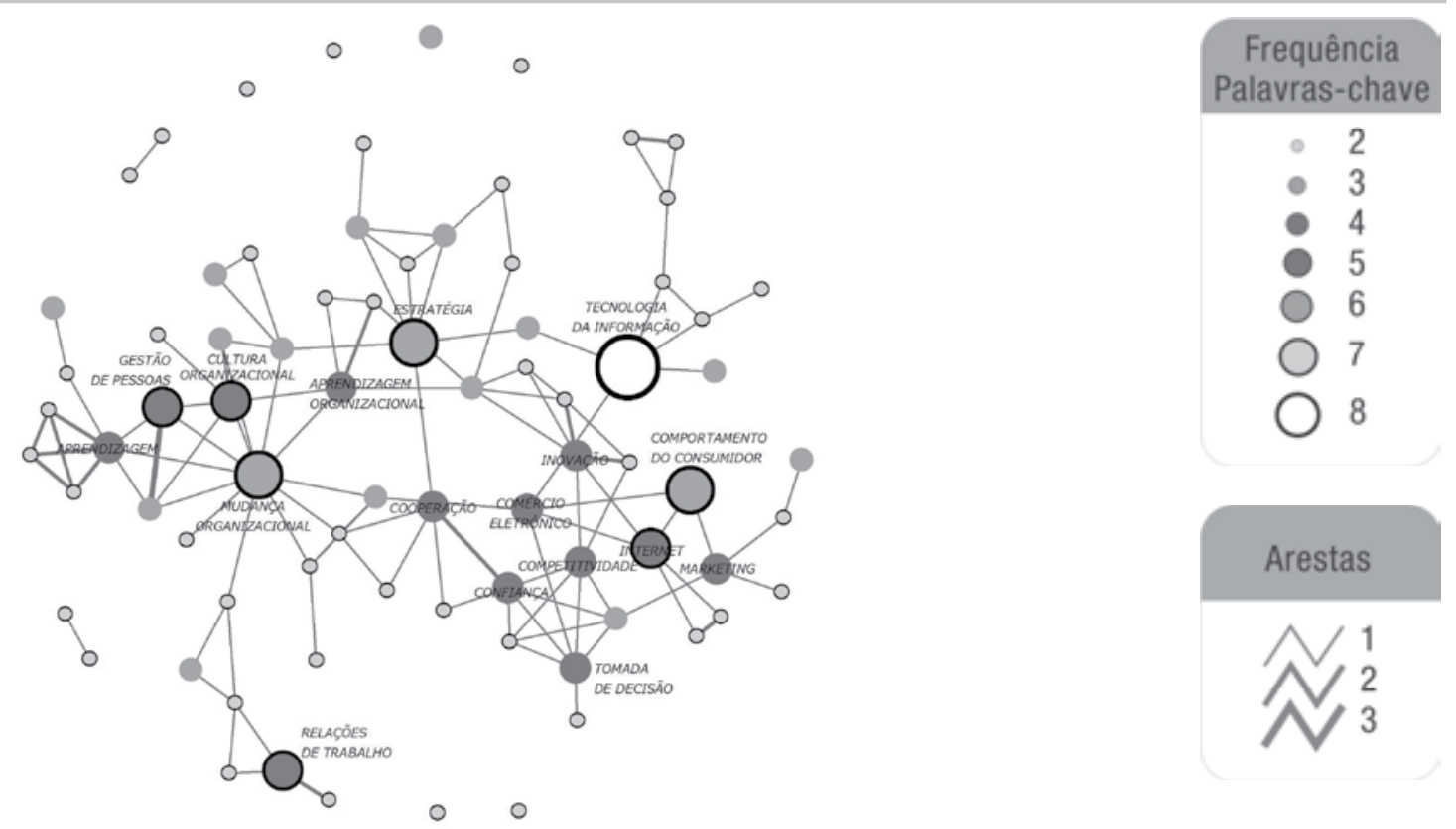


terminado contexto (FEINBERG, 2009; LUNARDI, CASTRO, MONAT, 2008). As 100 palavras-chave mais frequentes estão representadas com destaque de acordo com sua frequência na nuvem de palavras abaixo.

Análises similares foram realizadas com os títulos dos artigos da RAE-eletrônica, considerando os subtítulos, quando existentes, em conjunto, e com os resumos em Português. Termos estruturais (artigos, preposições, verbos de ligação etc.) foram desconsiderados. Os resumos compreendem textos com, no máximo, 1.100 caracteres (com espaços), o que aumenta a frequência de palavras relevantes nesta análise. A Tabela 12 apresenta as palavras mais frequentes nos títulos e nos resumos.

Nota-se similaridade com a frequência de palavras-chave para os termos "gestão", "organizacional" e "trabalho". Porém, o conceito "Brasil", que regionaliza o contexto geográfico da Administração nos temas abordados pela $R A E$-eletrônica, é a segunda palavra mais frequente nos títulos. As palavras "empresas", "trabalho" e "resultados" são as que mais se destacaram nos resumos.

Considerando as seções mais relevantes da $R A E$ eletrônica, em número de artigos, a análise de frequência de palavras nos resumos apresenta variações

\section{Tabela 11 - Centralidade das 20 palavras-chave mais influentes dos artigos da RAE-eletrônica de 2002 a 2010}

\begin{tabular}{|c|c|c|}
\hline Palavra-chave & $\begin{array}{l}\text { Centralidade } \\
\text { de Grau }\end{array}$ & $\begin{array}{l}\text { Centralidade de } \\
\text { Intermediação }\end{array}$ \\
\hline Mudança Organizacional & 12 & 983,6 \\
\hline Tecnologia da Informação & 9 & 632,3 \\
\hline Participação & 4 & 371,0 \\
\hline Comércio Eletrônico & 5 & 370,4 \\
\hline Estratégia & 6 & 322,9 \\
\hline Estrutura Organizacional & 4 & 309,0 \\
\hline Inovação & 9 & 271,6 \\
\hline Tributação & 4 & 269,9 \\
\hline Gestão Ambiental & 5 & 265,7 \\
\hline Marketing & 5 & 264,2 \\
\hline Aprendizagem & 10 & 253,0 \\
\hline Desempenho Empresarial & 6 & 243,2 \\
\hline Aprendizagem Organizacional & 6 & 223,2 \\
\hline Cooperação & 6 & 215,8 \\
\hline Comportamento do Consumidor & 3 & 211,9 \\
\hline Internet & 6 & 208,2 \\
\hline Controle Social & 4 & 195,0 \\
\hline Gestão do Conhecimento & 3 & 195,0 \\
\hline Confiança & 7 & 158,1 \\
\hline Complexidade & 5 & 144,3 \\
\hline
\end{tabular}


significativas, pertinentes aos temas específicos de cada seção, conforme a Tabela 12. As palavras "satisfação" e "pesquisa" são as mais frequentes para os 25 artigos de Marketing. "Organizações" e "organizacional" destacam-se entre os 42 artigos de Organizações, "trabalho" e "gestão" são os termos mais frequentes para os 26 artigos de Gestão de Pessoas e "empresas" e "resultados" destacam-se entre os 20 artigos de Estratégia.

Finalmente, o corpo do texto dos artigos também foi analisado. Para tal, nesse caso, termos no plural e no singular foram unificados. A nuvem de palavras com os 100 termos mais fre- quentes, com destaque para as 15 mais, estão na Figura 8.

As palavras mais empregadas nos 240 artigos da RAE-eletrônica são termos aplicados exaustivamente pelos pesquisadores de Administração em suas obras em Português. Pouco há a acrescentar a essa simples e definitiva constatação.

Observa-se que as palavras mais frequentes nos textos da RAE-eletrônica obedecem à Primeira Lei de Zipf (ZIPF, 1949), que indica que existe uma relação aproximada entre a frequência de uma dada palavra e sua posição no ranking das palavras mais frequentes (GUEDES e BORSCHIVER, 2005).

Figura 7 - Nuvem das palavras-chave mais citadas nos artigos da RAE-eletrônica de 2002 a 2010

\begin{tabular}{|l|r|}
\hline \multicolumn{1}{|c|}{ Palavra-chave } & Frequência \\
\hline Gestão & 37 \\
\hline Organizacional & 32 \\
\hline Aprendizagem & 18 \\
\hline Trabalho & 18 \\
\hline Tecnologia & 16 \\
\hline Análise & 13 \\
\hline Avaliação & 13 \\
\hline Estratégia & 12 \\
\hline Informação & 12 \\
\hline Mercado & 12 \\
\hline Social & \\
\hline
\end{tabular}

ética produçàopolticas

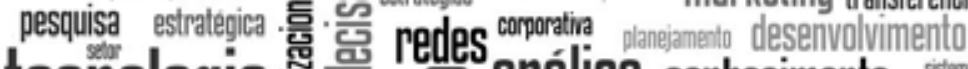
techologia

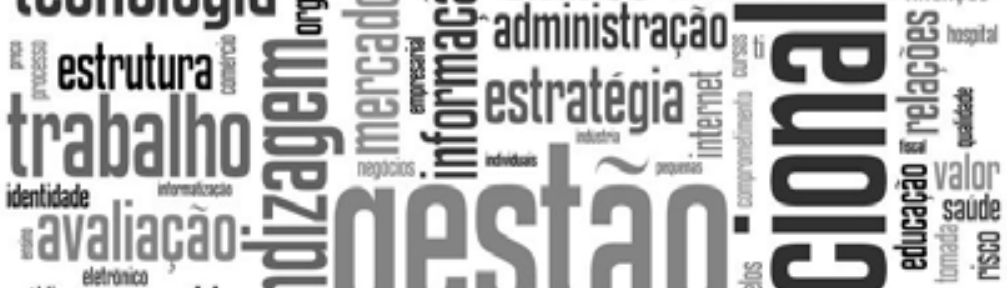

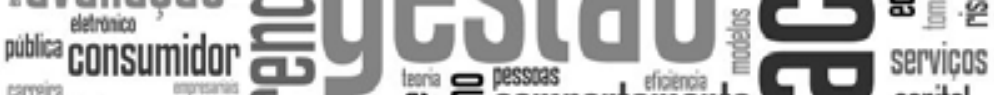

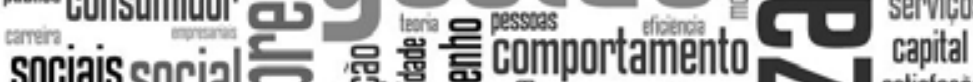

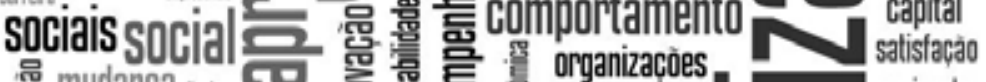
营 mudanGa cientes 总 renesentactes treinamento tomacas cooperacà̃o

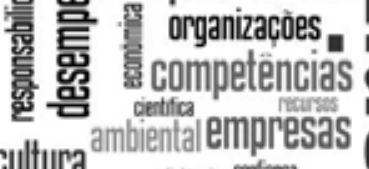

suprimentos oretica empresas distania contanca

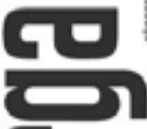




\section{CONSIDERAĢÕES FINAIS}

A investigação analítica sobre o acervo da $R A E$ eletrônica mostrou muita diversidade de autoria, o que é próprio de uma revista que busca a diversificação de opiniões e pontos de vista. Seu acervo relativamente pequeno, no entanto, não permite que façamos inferências ou comparações com a produtividade dos autores, conforme sugere a Lei Bibliométrica de Lotka (VANTI, 2002).

Observou-se também muita colaboração científica entre instituições por meio de coautorias, destacando a FGV-EAESP, a USP e a UFRGS como as de maior impac- to na produção da revista, devido ao grande número de autorias, coautorias com outras instituições e grau de intermediação do fluxo de informações no campo da Administração, mesmo ressalvando que estudos dessa natureza normalmente lidam com milhares de atores em suas redes. Notou-se também significativo interesse dos autores nacionais, e da própria $R A E-$ eletrônica, pela produção em parceria.

A preferência por citações a livros e periódicos é muito superior a artigos de congresso. Entre os periódicos mais influentes, destacam-se a $R A E$ e muitos periódicos internacionais, seguidos da $R A C, R A P$, Rausp e a própria $R A E$-eletrônica. Os congressos pro-

\section{Tabela 12 - Palavras mais frequentes nos títulos e nos resumos dos artigos da RAE-eletrônica de 2002 a 2010}

\begin{tabular}{|c|c|c|c|}
\hline \multicolumn{2}{|c|}{ Títulos } & \multicolumn{2}{|c|}{ Resumos } \\
\hline Palavra & Frequência & Palavra & Frequência \\
\hline Gestão & 23 & Empresas & 164 \\
\hline Brasil & 22 & Trabalho & 104 \\
\hline Análise & 17 & Resultados & 90 \\
\hline Empresas & 13 & Pesquisa & 78 \\
\hline Organizacional & 12 & Análise & 77 \\
\hline Organizações & 12 & Organizações & 74 \\
\hline Trabalho & 11 & Gestão & 71 \\
\hline Caso & 10 & Organizacional & 63 \\
\hline Administração & 9 & Objetivo & 54 \\
\hline Desempenho & 8 & Processo & 54 \\
\hline Inovação & 8 & Meio & 53 \\
\hline Pesquisa & 8 & Modelo & 48 \\
\hline Social & 8 & Brasil & 47 \\
\hline Tecnologia & 8 & Mercado & 44 \\
\hline
\end{tabular}




\section{Figura 8 - Nuvem das palavras mais citadas no corpo do texto dos artigos da RAE-eletrônica de 2002 a 2010}

\begin{tabular}{|l|r|}
\hline Palavra & Frequiência \\
\hline Empresa & 5.602 \\
\hline Organização & 3.261 \\
\hline Trabalho & 3.169 \\
\hline Processo & 2.816 \\
\hline Relação & 2.769 \\
\hline Social & 2.460 \\
\hline Modelo & 2.214 \\
\hline Pesquisa & 2.019 \\
\hline Resultado & 2.019 \\
\hline Análise & 1.967 \\
\hline Informação & 1.701 \\
\hline Produto & 1.624 \\
\hline Mercado & 1.574 \\
\hline Ação & 1.562 \\
\hline Gestão & 1.462 \\
\hline
\end{tabular}

movidos pela Anpad, em especial o Enanpad, são os mais citados.

Guardadas as ressalvas de representatividade, discutidas ao longo deste artigo, o acervo da RAE-eletrônica reflete, em grande parte, o universo da produção acadêmica recente no campo da Administração.

O uso combinado de técnicas convencionais de bibliometria com as análises de redes sociais e as análises geográficas permitiu um entendimento da estrutura e das características de relacionamento entre autores, instituições e entre assuntos (por meio das palavras-chave) ocorrido ao longo dos nove anos da revista.

A missão foi inicialmente concluída. E o tom despretensioso manteve-se. Muitas outras análises certamente advirão com base no que aqui foi exposto. Espera-se que as diversas técnicas, outrora aplicadas em mundos e contextos distintos - em especial, as análises de redes sociais e as análises geográficas possam caminhar lado a lado, sob o pano de fundo da bibliometria e ciências correlatas.

Mais ainda, abre-se um horizonte muito rico de investigação sobre o acervo da ora cinquentenária $R A E$. Dois mil artigos e meio século de história aguardam-nos.

\section{REFERÊNCIAS}

ACEDO, F. e outros. Co-authorship in management and organizational studies: an empirical and network analysis. Journal of Management Studies, v. 43, n. 5, p. 957-983, 2006.

ANSELIN, L. Spatial econometrics: methods and models. Dordrecht: Kluwer Academic, 1988.

ARANHA, F; FIGOLI, S. Geomarketing: memórias de viagem. São Paulo, 2001. Documento eletrônico. Disponível sob pedido a francisco.aranha@fgv.br.

ARANHA, F; FRANCISCO, E; PONCHIO, M; TINOCO, T; MOURA, A. Avaliando relevância e influência em artigos científicos. In: CONGRESSO ANUAL DE TECNOLOGIA DA INFORMAÇÃO (CATI), 2004, São Paulo. 1 CD-ROM, v. 1, p. 1-16, 2004.

ARKADER, R. A pesquisa científica em gerência de operações no Brasil. RAE-revista de administração de empresas, v. 43, n. 1, p. 70-80, 2003.

BADDELEY, A; TURNER, R. Spatstat: an R package for analyzing spatial point patterns. Journal of Statistical Software, v. 12, n. 6, p. 1-42, 2005. 
BARBOSA, A. C. Q. A produção acadêmica em recursos humanos no Brasil: fato ou ficção? RAE-eletrônica, v. 3, n. 2, art. 27,8 p., 2004 .

BERTIN, J. La graphique et le traitement graphique del'information. Paris: Flammarion, 1977.

BORGATTI, S. P; EVERETT, M. G; FREEMAN, L. C. Ucinet for Windows: software for social network analysis. Harvard: Analytic Technologies, 2002.

BRANDES, U. Faster evaluation of shortest-path based centrality indices. Konstanzer Schriften in Mathematik und Informatik, Universität Konstansz, ISSN 1430-3558, n. 120 , maio 2000 .

BRANDES, U; KENIS, P; WAGNER, D. Communicating centrality in policy network drawings. IEEE Transactions on Visualization and Computer Graphics, v. 9, n. 2, p. 241-253, abr./maio 2003.

BUTTS, C. T. Network: a package for managing relational data in R. Journal of Statistical Software, v. 24, n. 2, 36 p., fev. 2008.

BUTTS, C. T. SNA: tools for social network analysis. R package version 2.2-0. 2010. Disponível em: http://CRAN. R-project.org/package=sna. Acesso em 28.01.2011.

BUTTS, C. T; HANDCOCK, M. S; HUNTER, D. R. Network: classes for relational data. R package version 1.6. Irvine, 2011. Disponível em http://statnet.org. Acesso em: 28.01.2011.

CALDAS, M. P; TINOCO, T; CHU, R. A. Análise bibliométrica dos artigos de RH publicados no Enanpad na década de 1990: um mapeamento a partir das citações dos heróis, endogenias e jactâncias que fizeram a história recente da produção científica na área. In: ENCONTRO ANUAL DA ASSOCIAÇÃO NACIONAL DOS PROGRAMAS DE PÓS-GRADUAÇÃO EM ADMINISTRAÇÃO, 27, [2003], Atibaia. Resumo dos Trabalhos Enanpad 2003. Rio de Janeiro: Anpad, 2003.

CALDAS, M. P; TINOCO, T. Pesquisa em gestão de recursos humanos nos anos 1990: um estudo bibliométrico. RAE-revista de administração de empresas, v. 44, n. 3, p. 100-114, 2004a.

CALDAS, M. P.; TINOCO, T. Sobre mapas e topógrafos: uma tréplica a Barbosa (2004) e Mattos (2004). RAE-eletrônica, v. 3 , n. 2, art. 28,7 p, 2004b.

CÂmarA, G; CAMARGO, E. Análise espacial de dados geográficos. In: CONGRESSO GEOBRASIL , [2002], São Paulo. Seminários GEOBrasil 2002. Curitiba: MundoGEO, 2002.
CARDOSO, R. L; MENDONÇA NETO, O. R; RICCIO, E. L; SAKATA, M. C. G. Pesquisa científica em contabilidade entre 1990 e 2003. RAE-revista de administração de empresas, $\mathrm{v}$. 45 , n. 2, p. 34-45, 2005.

CARVALHO, M. S. Aplicação de métodos de análise espacial na caracterização de áreas de risco à saúde. 1997. Tese de Doutorado em Engenharia Biomédica, Coppe/UFRJ, Rio de Janeiro, 1997.

CSARDI, G; NEPUSZ, T. The igraph software package for complex network research, InterJournal, Complex Systems 1695, 2006. Disponível em: http://igraph.sf.net. Acesso em 28.01.2011.

DIGGLE, P. J. Statistical analysis of spatial point patterns. London: Academic Press, 1983.

DOBROV, G. M; KARENNOI, A. The informational basis of scientometrics. In: MIKHAILOV, A. I. (Ed). On theoretical problems of informatics. Moscow: Viniti/FID, 1969.

FEINBERG, J. Wordle. Disponível em: http://www.wordle. net. Acesso em 28.3.2009.

FOWLER, R. J. Database Implementation for the TIN data structure, Technical Report 11, ONR Contract \#n0001475-c-088 6, Dept. of Geography, Simon Fraser Univ, B. C, Burnaby, 1976.

FRANCISCO, E. GIS não geográfico? Revista InfoGEO, Curitiba, n. 39, ano 7, p. 38-39, 2005.

FRANCISCO, E. Indicadores de renda baseados em consumo de energia elétrica: abordagens domiciliar e regional na perspectiva da estatística espacial. 2010. 381 p. Tese de Doutorado em Administração de Empresas, Escola de Administração de Empresas de São Paulo da Fundação Getulio Vargas, São Paulo, 2010.

FRANCISCO, E; ARANHA, F; PONCHIO, M; MOURA, A. Evaluating relevance and influence in scientific articles. In: BUSINESS ASSOCIATION OF LATIN AMERICAN STUDIES ANNUAL CONFERENCE (BALAS), 2005, Madrid. The Balas 2005 Conference Proceedings, v. 1, p. 1-16. San Diego: Balas, 2005.

FRUCHTERMAN, T. M. J; REINGOLD, E. M. Graph drawing by force-directed placement. Software: Practice and Experience, v. 21, n. 11, p. 1129-1164, 1991.

GARFIELD, E. Citation indexes: new paths to scientific knowledge. The Chemical Bulletin, v. 43, n. 4, 11 p., abr. 1956.

GARFIELD, E. Citation indexing: its theory and application in science, technology and bumanities, New York: Wiley, 1979. 
GREGORI, R. G; LINK, F. A cientifização dos negócios: visão geral e estudo de caso do setor financeiro. In: GUIMARÃES, J. R. S. Demografia dos negócios: campo de estudo, perspectivas e aplicações. Campinas: ABEP, 2006. p. 97-130.

GUEDES, V. L. S; BORSCHIVER, S. Bibliometria: uma ferramenta estatística para a gestão da informação e do conhecimento em sistemas de informação, de comunicação e de avaliação científica e tecnológica. In: ENCONTRO NACIONAL DE CIÊNCIA DA INFORMAÇÃO, 6, 2005, Salvador. Anais. Salvador, p. 1-18, 2005.

HANNEMAN, R. A; RIDDLE, M. Introduction to social network methods. Riverside: University of Califórnia, 2005. Disponível em: http://faculty.ucr.edu/ hanneman/nettext/ index.html. Acesso em 28.01.2011.

HJOREGAARD, C. F; INGWERSEN, P. Data set isolation for bibliometric online analyses of research publications: fundamental methodological issues. Journal of the Society for Information Science, v. 48, n. 3, p. 205-217, 1997.

KAMADA, T; KAWAI, S. An algorithm for drawing general undirected graphs. Information Processing Letters, v. 31, n. 1, p. 7-15, abr. 1989 .

KOBASHI, N. Y; SANTOS, R. N. M. Institucionalização da pesquisa científica no Brasil: cartografia temática e de redes sociais por meio de técnicas bibliométricas, Transinformação, Campinas, v. 18, n. 1, p. 27-36, 2006.

KOSTOFF, R. N. Research impact quantification. RED Management, v. 24, n. 3, p. 207-213, jul. 1994.

KOSTOFF, R. N. The use and misuse of citation analysis in research evaluation. Scientometrics, v. 43, n. 1, p. 27-43, mai. 1998.

LEAL, R. P. C; OLIVEIRA, J; SOLURI, A. F. Perfil da pesquisa em finanças no Brasil. RAE-revista de administração de empresas, v. 43, n. 1, p. 91-104, 2003.

LEITE FILHO, G. A. Padrões de produtividade de autores em periódicos de congressos na área de contabilidade no Brasil: um estudo bibliométrico. In: CONGRESSO USP DE CONTROLADORIA E CONTABILIDADE, 6, 2006, São Paulo. Anais. São Paulo: FEA/USP, 2006. 1 CD-ROM.

LEWIN-KOH, N. J; BIVAND, R. Maptools: tools for reading and handling spatial objects. $\mathrm{R}$ package version 0.7 26. 2009. Disponível em: http://CRAN.R-project.org/ package $=$ maptools. Acesso em 11.10.2009. With contributions by Edzer J. Pebesma, Eric Archer, Adrian Baddeley, Hans-Jörg Bibiko, Stéphane Dray, David Forrest, Patrick Giraudoux, Duncan Golicher, Virgilio Gómez Rubio, Patrick Hausmann, Thomas Jagger, Sebastian P. Luque, Don
MacQueen, Andrew Niccolai and Tom Short.

LUNARDI, M. S; CASTRO, J. M. F. C; MONAT, A. S. Visualização dos resultados do Yahoo em nuvens de texto: uma aplicação construída a partir de web services. InfoDesign Revista Brasileira de Design da Informação, v. 5, n. 1, p. 21-35, 2008.

MACHADO-DA-SILVA, C. L; GUARIDO FILHO, E. R; ROSSONI, L. Campos organizacionais: seis diferentes leituras e a perspectiva de estruturação. Revista de Administração Contemporânea (RAC), v. 10, n.spe, p. 159-196, $2006 \mathrm{a}$.

MACHADO-DA-SILVA, C. L; GUARIDO FILHO, E. R; ROSSONI, L. Organizational fields and the structuration perspective: analytical possibilities. Brazilian Administration Review (BAR), v. 3, n. 2, p. 32-56, 2006b.

MACHADO-DA-SILVA, C. L; GUARIDO FILHO, E. R; ROSSONI, L; GRAEFF, J. F. Periódicos brasileiros de administração: análise bibliométrica de impacto no triênio 20052007. RAC Eletrônica (Online), Curitiba, v. 2, n. 3, art. 1, p. 351-373, 2008.

MARTINS, G. S; ROSSONI, L; CSILLAG, J. M; MARTINS, M. E; PEREIRA, S. C. F. Gestão de operações no Brasil: uma análise do campo científico a partir da rede social de pesquisadores. RAE-eletrônica, v. 9, n. 2, art. 8, 2010.

MATTOS, P. L. C. L. "Bibliometria": a metodologia acadêmica convencional em questão. RAE-eletrônica, v. 3, n. 2, art. 26, 2004, 6 p.

MELlO, C. M; CRUBEllate, J. M; ROSSONI, L. Dinâmica de relacionamento e prováveis respostas estratégicas de programas brasileiros de pós-graduação em administração à avaliação da capes: proposições institucionais a partir da análise de redes de coautorias. Revista de Administração Contemporânea (Impresso), v. 14, n. 3, p. 434-457, 2010.

MELlO, C. M; CRUBellate, J. M; ROSSONI, L. Rede de coautorias entre docentes de programas brasileiros de pósgraduação (stricto sensu) em administração: aspectos estruturais e dinâmica de relacionamento. Revista de Administração Mackenzie (RAM), v. 10, n. 5, p. 130-155, 2009.

MENDONÇA NETO, O. R; RICCIO, E. L; SAKATA, M. C. G. Dez anos de pesquisa contábil no brasil: análise dos trabalhos apresentados nos Enanpads de 1996 a 2005. RAE-revista de administração de empresas, São Paulo, v. 49, n. 1, p. 62-73, 2009.

MOODY, J. The structure of a social science collaboration network: disciplinary cohesion from 1963 to 1999. American Sociological Review, v. 69, n. 2, p. 213-238, 2004.

NEWMAN, M. The structure of scientific collaboration networks. Proceedings of National Academic Sciences, v. 98, n. 2, p. 404-409, 2001. 
PEUCKER, T. K; FOWLER, R. J; LITTLE, J. J; MARK, D. M. Digital representation of three-dimensional surfaces by triangulated irregular networks (TIN). Technical Report 10, ONR Contract \#N00014-75-c-0886, Dept. of Geography, Simon Fraser Univ, Burnaby, B. C, 1977.

$\mathrm{R}$ DEVELOPMENT CORE TEAM. R: a language and environment for statistical computing. R Foundation for Statistical Computing, Vienna. ISBN 3-900051-07-0, 2011. Disponível em: http://www.R-project.org. Acesso em 28.01.2011.

RIPPLEY, B. D. Spatial statistics. New York: John Wiley and Sons, 1981.

RIPPLEY, B. D. Statistical inference for spatial processes. Cambridge: Cambridge University Press, 1988.

ROSSONI, L; MACHADO-DA-SILVA, C. L. Análise institucional da construção do conhecimento científico em mundos pequenos. Faces (FACE/FUMEC), v. 7, n. 1, p. 25-43, 2008.

ROSSONI, L; GUARIDO FILHO, E. R. Cooperação entre programas de pós-graduação em administração no brasil: evidências estruturais em quatro áreas temáticas. Revista de Administração Contemporânea (RAC), v. 13, n. 3, p. 366-390, 2009.

SPINAK, E. Diccionario enciclopédico de bibliometría, cienciometría e informetría. Montevideo: UNESCO, 1996. $245 \mathrm{p}$.

TAGUE-SUTCKIFFE, J. An introduction to informetrics. Information Processing \& Management, v. 28, n. 1, p. 1-3, 1992.

TOBLER, W. R. A computer movie simulating urban growth in the Detroit region. Economic Geography, v. 46, n. 2, p. 234-240, 1970.

TONELLI, M. J; CALDAS, M. P; LACOMBE, B. M. B; TINO$\mathrm{CO}, \mathrm{T}$. Produção acadêmica em recursos humanos no Brasil: 1991-2000. RAE-revista de administração de empresas, v. 43, n. 1, p. 105-122, 2003.

TUFTE, E. R. The visual display of quantitative information. Connecticut: Graphics Press, 1983.

VANTI, N. Da bibliometria à webometria: uma exploração conceitual dos mecanismos utilizados para medir o registro da informação e a difusão do conhecimento. Ciência da Informação, v. 31, n. 2, p. 152-162, 2002.

WASSERMAN, S; FAUST, K. Social network analysis: methods and applications. Cambridge: Cambridge University Press, 1994.
WATTS, D. Small worlds: the dynamics of networks between order and randomness. Princeton: Princeton University Press, 1999.

WATTS, D; STROGATZ, S. Collective dynamics of "smallworld" networks. Nature, ed. 393, p. 440-442, 1998.

WEST, D. B. Introduction to graph theory. Upper Saddle River: Prentice Hall, 1996.

WORMELL, I. Informetria: explorando bases de dados como instrumento de análise. Ciência da Informação, v. 27, n. 2, p. 210-216, 1998.

ZIPF, G. K. Human behavior and the principle of least effort. Cambridge: Addison Wesley, 1949. 